\title{
A New OD Diesel HCCl Combustion Model Derived from a 3D CFD Approach with Detailed Tabulated Chemistry
}

\author{
A. Dulbecco ${ }^{1}$, F.-A. Lafossas ${ }^{1}$, G. Mauviot ${ }^{1}$ and T.J. Poinsot ${ }^{2}$ \\ 1 Institut français du pétrole, IFP, 1-4 avenue de Bois-Préau, 92852 Rueil-Malmaison Cedex - France \\ 2 CERFACS, 42 avenue G. Coriolis, 31057 Toulouse Cedex 1 - France \\ e-mail: alessio.dulbecco@ifp.fr - francois-a.lafossas@toyota-europe.com - gilles.mauviot@ifp.fr - thierry.poinsot@cerfacs.fr \\ * Corresponding author
}

\begin{abstract}
Résumé - Un nouveau modèle 0D pour la simulation de la combustion Diesel HCCI obtenu par réduction d'un code CFD 3D utilisant une méthode de chimie complexe tabulée - Cet article présente une nouvelle approche phénoménologique $0 \mathrm{D}$ à la modélisation numérique de la combustion Diesel HCCI. Le modèle a été obtenu par réduction du modèle CFD 3D TKI-PDF (Cinétique Chimique Tabulée pour la détection de l'auto-allumage couplée avec une Fonction à Densité de Probabilité présumée) développé à l'IFP; sa formulation est basée sur des considérations de type physique afin de prendre en compte les différents phénomènes qui interviennent dans le cylindre pendant le processus de combustion et leurs interactions. Les aspects relatifs à l'évaporation du carburant, à la pénétration du spray, à la turbulence, à la formation du mélange et à la cinétique chimique ont été étudiés en détail. L'apport original de ce travail concerne la description du mécanisme de formation et d'évolution du mélange air/carburant (au sein de la zone de mélange) et de son couplage avec la cinétique de combustion. Afin de s'affranchir des limitations liées au formalisme 0D (manque de notion d'espace), différents outils couramment adoptés en modélisation 3D ont été utilisés. La théorie relative aux PDF présumées a été adaptée au formalisme 0D pour la description de la distribution de la fraction de mélange dans la zone de mélange. Cette distribution est couplée avec la théorie relative à l'évaporation d'une goutte qui définit les états thermodynamiques caractérisant la composition locale du mélange. L'évolution temporelle du spray, en terme de volume et de masse de gaz entraîné, est déduite à partir des lois de conservation de la masse, de quantité de mouvement et d'énergie. Un modèle $\kappa-\epsilon$ adapté a été utilisé pour prendre en compte les effets de la turbulence dans le cylindre qui, dans les Moteurs à Combustion Interne (ICE), joue un rôle très important principalement en ce qui concerne le processus de mélange. La cinétique chimique, qui induit le taux de dégagement d'énergie, est déterminée en utilisant une méthode de tabulation de la chimie complexe inspirée de la méthode FPI (Prolongation aux Flammes de la méthode ILDM Intrinsic Low Dimensional Manifold)). Cette méthode permet de simuler une grande plage de régimes de combustion prenant en compte la présence de Gaz Brûlés Recirculés $(E G R)$ dans le mélange de gaz. Les résultats du modèle $0 \mathrm{D}$ sont comparés avec les résultats du modèle 3D équivalent. Finalement, le modèle 0D est validé sur une large base de données expérimentales.
\end{abstract}

Abstract - A New OD Diesel HCCI Combustion Model Derived from a 3D CFD Approach with Detailed Tabulated Chemistry - This paper presents a new OD phenomenological approach to the numerical modelling of Diesel HCCI combustion. The model is obtained through the reduction of 
TKI-PDF (Tabulated Kinetics for Ignition, coupled with presumed Probability Density Function) 3D CFD model developed at the IFP. Its formulation is based on physical considerations, to take into account the main phenomena and their mutual interactions that take place in the cylinder during the combustion process. Aspects relating to spray penetration, fuel evaporation, turbulence, mixture formation and chemical kinetics have been studied in detail. The original contribution of this work concerns the modelling of the formation and evolution of the equivalence ratio stratification around the spray, and of its connection to combustion kinetics. In order to achieve this, different tools commonly adopted in 3D modelling have been adapted to OD modelling. Presumed PDF theory has been extended to a OD formalism in order to characterize the mixture-fraction distribution. This approach has then been coupled with droplet-evaporation theory in order to have access to the thermodynamic conditions characterizing the mixture. The temporal evolution of the spray is computed in terms of volume and the entrained mass of gases, starting from conservation laws for mass, momentum and energy. An adapted $\kappa-\epsilon$ model is used to take into account the turbulence in the cylinder, which is very important, in an ICE (Internal Combustion Engine), especially during the mixing process. Further, combustion heatrelease is computed using an adapted detailed tabulated chemistry method inspired by the FPI (Flame Prolongation of ILDM (Intrinsic Low Dimensional Manifold)) theory. This look-up table allows the simulation of a large range of combustion regimes, since it takes into account the presence of EGR (Exhaust Gas Recirculation) in the mixture. The results of the OD model are compared in an initial step to the 3D CFD results. Finally, the OD model is validated against a wide experimental database.

\section{NOMENCLATURE Latin abbreviations}

\begin{tabular}{|c|c|c|}
\hline$a$ & {$[-]$} & constant coefficient $(a=0.66)$ \\
\hline$b$ & {$[-]$} & constant coefficient $(b=0.41)$ \\
\hline$B$ & {$[-]$} & transfer number at steady-state \\
\hline$B_{m}$ & {$[-]$} & mass transfer number \\
\hline$B_{t}$ & {$[-]$} & thermal transfer number \\
\hline$c$ & {$[-]$} & progress variable \\
\hline$C_{a}$ & {$[-]$} & orifice area-contraction coefficient \\
\hline$C_{d}$ & {$[-]$} & orifice discharge coefficient \\
\hline$C_{\text {diss }}$ & {$[-]$} & $\widetilde{Z " 2}$ dissipation-term coefficient \\
\hline$C_{e v}$ & {$[-]$} & evaporation-rate coefficient \\
\hline$C_{K}$ & {$[-]$} & $\tilde{K}$ dissipation-term coefficient \\
\hline$C_{p}$ & {$[\mathrm{~J} / \mathrm{kg} / \mathrm{K}]$} & constant pressure specific heat \\
\hline$C_{v}$ & {$[\mathrm{~J} / \mathrm{kg} / \mathrm{K}]$} & constant volume specific heat \\
\hline$C_{\theta}$ & {$[-]$} & spray opening-angle coefficient \\
\hline$C_{K}$ & {$[-]$} & $\tilde{\kappa}$ dissipation-term coefficient \\
\hline$d_{h}$ & {$[\mathrm{~m}]$} & injector hole diameter \\
\hline$D$ & {$[\mathrm{~m}]$} & droplet diameter \\
\hline$E_{c}$ & {$[\mathrm{~J}]$} & kinetic energy \\
\hline$h$ & {$[\mathrm{~J} / \mathrm{kg}]$} & enthalpy \\
\hline$k$ & {$[\mathrm{~J} / \mathrm{m} / \mathrm{s} / \mathrm{K}]$} & thermal conductivity \\
\hline$\tilde{K}$ & {$[\mathrm{~J} / \mathrm{kg}]$} & mean specific kinetic energy \\
\hline$L$ & {$[\mathrm{~m}]$} & liquid-phase fuel penetration \\
\hline$L_{v}$ & {$[\mathrm{~J} / \mathrm{kg}]$} & latent heat of vaporization \\
\hline Le & {$[-]$} & Lewis number \\
\hline$m$ & {$[\mathrm{~kg}]$} & mass \\
\hline$m_{a}$ & {$[\mathrm{~kg}]$} & stoichiometric mass of air \\
\hline$m_{c y l}$ & {$[\mathrm{~kg}]$} & total in-cylinder gaseous mass \\
\hline$M$ & {$[\mathrm{~kg} / \mathrm{mol}]$} & molar mass \\
\hline$n$ & [mol] & mole number \\
\hline$n_{h}$ & {$[\mathrm{~m}]$} & number of injector holes \\
\hline
\end{tabular}

\begin{tabular}{|c|c|c|}
\hline$N_{K}$ & {$[-]$} & $\tilde{K}$ dissipation-term exponent \\
\hline$N_{\kappa}$ & {$[-]$} & $\tilde{\kappa}$ dissipation-term exponent \\
\hline$p$ & {$[\mathrm{~Pa}]$} & pressure \\
\hline$p_{c r}$ & {$[\mathrm{~Pa}]$} & critical pressure \\
\hline$p_{v}$ & {$[\mathrm{~Pa}]$} & fuel vapor pressure \\
\hline $\mathcal{P}$ & {$[-]$} & probability function \\
\hline $\mathcal{P}_{c o}$ & {$[-]$} & coupled probability function \\
\hline$q$ & {$[-]$} & constant coefficient $(q=2.2)$ \\
\hline$Q_{e v}$ & {$[\mathrm{~J} / \mathrm{s}]$} & fuel evaporation thermal flux \\
\hline$Q_{h u}$ & {$[\mathrm{~J} / \mathrm{s}]$} & fuel heat up thermal flux \\
\hline$Q_{t h}$ & {$[\mathrm{~J} / \mathrm{s}]$} & exchanged thermal flux \\
\hline$Q_{t o t}$ & {$[\mathrm{~J} / \mathrm{s}]$} & total thermal flux \\
\hline$r$ & {$[\mathrm{~m}]$} & radius \\
\hline $\mathcal{R}$ & {$[\mathrm{J} / \mathrm{mol} / \mathrm{K}]$} & universal gas constant \\
\hline$s$ & {$[-]$} & mass stoichiometric coefficient \\
\hline$S$ & {$[\mathrm{~m}]$} & spray penetration \\
\hline$t^{+}$ & {$[\mathrm{s}]$} & spray characteristic time-scale \\
\hline$t_{i n j}$ & {$[\mathrm{~s}]$} & relative injection time \\
\hline$T$ & {$[\mathrm{~K}]$} & temperature \\
\hline$T_{b}$ & {$[\mathrm{~K}]$} & normal boiling temperature \\
\hline$T_{c r}$ & {$[\mathrm{~K}]$} & critical temperature \\
\hline$U_{F_{l}}$ & {$[\mathrm{~m} / \mathrm{s}]$} & fuel injection velocity \\
\hline$v$ & {$\left[\mathrm{~m}^{3} / \mathrm{mol}\right]$} & molar volume \\
\hline$V$ & {$\left[\mathrm{~m}^{3}\right]$} & cylinder volume \\
\hline$V_{S}$ & {$\left[\mathrm{~m}^{3}\right]$} & spray volume \\
\hline$x^{+}$ & {$[\mathrm{m}]$} & spray characteristic length-scale \\
\hline$x_{0}$ & {$[\mathrm{~m}]$} & removed cone height \\
\hline$X$ & {$[-]$} & molar fraction \\
\hline$Y$ & {$[-]$} & mass fraction \\
\hline$Y_{l c}$ & {$[-]$} & mass fraction linear combination \\
\hline$Z$ & {$[-]$} & mixture fraction \\
\hline$\widetilde{Z " 2}$ & {$[-]$} & mixture fraction variance \\
\hline
\end{tabular}




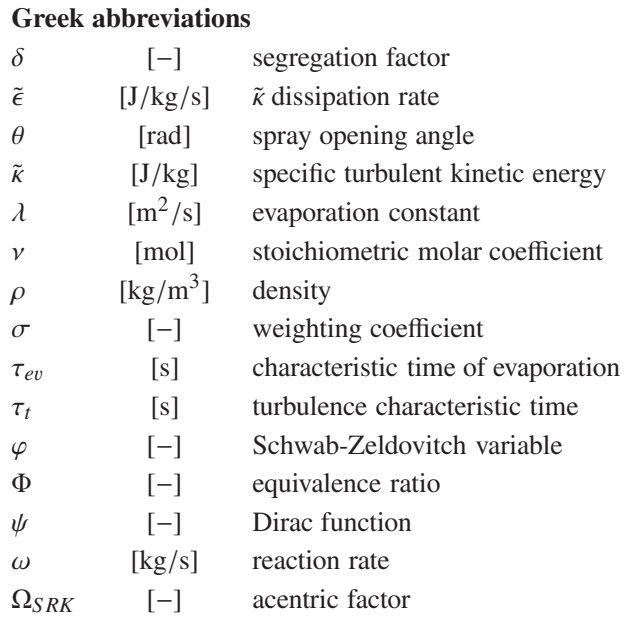

$\begin{array}{ll}\text { Superscripts } & \\ S / I & \text { higher/lower } \Phi \text { tabulated values } \\ 0 & \Phi \text { reference value }\end{array}$

$\begin{array}{ll}\text { Subscripts } & \\ A & \text { ambient gas } \\ c & \text { complementary mixture-fraction } \\ d s & \text { dissipation term } \\ e q & \text { chemical equilibrium conditions } \\ \text { esp } & \text { species } \\ F & \text { gaseous fuel } \\ F_{\text {inj }} & \text { injected fuel } \\ F_{l} & \text { liquid fuel } \\ g & \text { equivalent mixture } \\ i / o & \text { inlet/outlet } \\ m & \text { mass diffusion boundary layer } \\ m a x & \text { maximum value } \\ m i x & \text { mixture } \\ O & \text { oxidizer } \\ p r & \text { production term } \\ r & \text { EGR } \\ s & \text { liquid-gas interface } \\ S & \text { spray } \\ S / I & \text { higher/lower } X_{r} \text { tabulated values } \\ t & \text { thermal diffusion boundary layer } \\ w & \text { withdrawn ambient gas } \\ \beta-P D F & \text { normalized } \beta-P D F \text { variables } \\ \tau & \text { tracer (non reactive) conditions } \\ 0 & \text { reference value } \\ 1 / 3 & 1 / 3 \text { law reference variable } \\ \infty & \text { condition at infinity } \\ & \end{array}$

\section{INTRODUCTION}

Numerical simulation plays an increasingly important role in engine development processes; its most important advantage being due to the fact that, it is possible to perform a great number of numerical tests, at costs that are much lower than those associated with experiments. This becomes particularly important with future generations of ICE. In fact, in order to obtain best performance, engines are increasingly composed of complex system-layouts involving a great number of devices such as an EGR system, a CR (Common Rail) Direct Injection System, etc. Such systems need to be optimized [1-4].

In this context, a numerical engine simulator must be able to give an accurate estimate of the main values characterizing the performance of the engine, such as combustion heat release, combustion efficiency, and pollutant formation.

In the literature concerning both conventional Diesel and HCCI (Homogeneous Charge Compression Ignition) combustion, it is possible to distinguish two main classes of models, according to their purpose. The first class includes models adapted to global system simulation. Models in this class give access to fewer details of the combustion process, but lesser CPU times are required. Usually in this domain tabulated-base, empirical or phenomenological approaches are used [5-20]. The second class includes models adapted for research purposes. Models in this class give access to greater detail in the combustion process, but much more CPU time is required. Usually in this domain physical approaches are used [21-38].

This paper presents a new 0D approach to the modelling of Diesel HCCI combustion derived from the reduction of a 3D CFD model. The new model is able to accurately predict the combustion process, while requiring low $\mathrm{CPU}$ resources. These two aspects outline a model profile adapted to globalsystem simulation applications. In the following, a global overview of the model is given first. The two main parts of the model are subsequently presented and detailed: the spray and the combustion modelling. Partial validations of these models have been performed using 3D results and experimental data. Finally, validation of the global combustion model is done by comparison with experimental results. The paper ends with a discussion of the model improvements and perspectives.

\section{GLOBAL OVERVIEW OF THE MODEL}

Conventional Diesel and HCCI combustion modes are governed by different physical mechanisms.

In conventional Diesel combustion, the mixture inside the cylinder is characterized by a high fuel mass fraction stratification. The first site of auto-ignition appears inside the spray, where chemical and thermodynamic conditions are the most favourable. The most important challenge concerning auto-ignition phase description is to capture the shortest ignition delay. Heat release, due to combustion at the first site, subsequently favors the multiplication of auto-ignition sites. This chain reaction leads to the sharp heat release process typical of the premixed Diesel combustion phase. The remaining fuel burns in a diffusion flame and the heat release is governed by the mixing process. In this phase, turbulence plays the most important role. 
In HCCI combustion, the mixture inside the cylinder can be considered as homogeneous. Hence chemical kinetics plays the most important role in the combustion process. Because of the homogeneity of the mixture, all of the gas auto-ignites simultaneously. As a consequence, HCCI combustion is characterized by a stiff heat release process. For these reasons, a deep understanding of the spray formation mechanic is necessary [39-44].

In a general situation, the two combustion regimes are not so well distinguished. A modelling challenge, therefore, is to be able to manage all of the different scenarios. Moreover, the presence of EGR in the cylinder modifies the chemical kinetics, and phenomena, such as cold flames, could appear at the beginning of the fuel oxidation process.

The original modelling solution proposed in this work is derived from a reduction of the TKI-PDF 3D CFD model $[33,34,45]$. It has the potential to take into account all of the different phenomena, taking advantage of the common tools used in sub-grid 3D modelling. The first of these is the use of a presumed PDF $[12,13,46]$ in order to describe the distribution of fuel inside the spray region. The second is the use of a look-up table in order to take chemical kinetics into account This technique has been inspired by the FPI theory [47]. The third tool is the use of an adapted $\kappa-\epsilon$ model to simulate the impact of turbulence on the mixing and combustion processes.

The synoptical diagram of the complete Diesel HCCI combustion model is presented in Figure 1. As shown, the

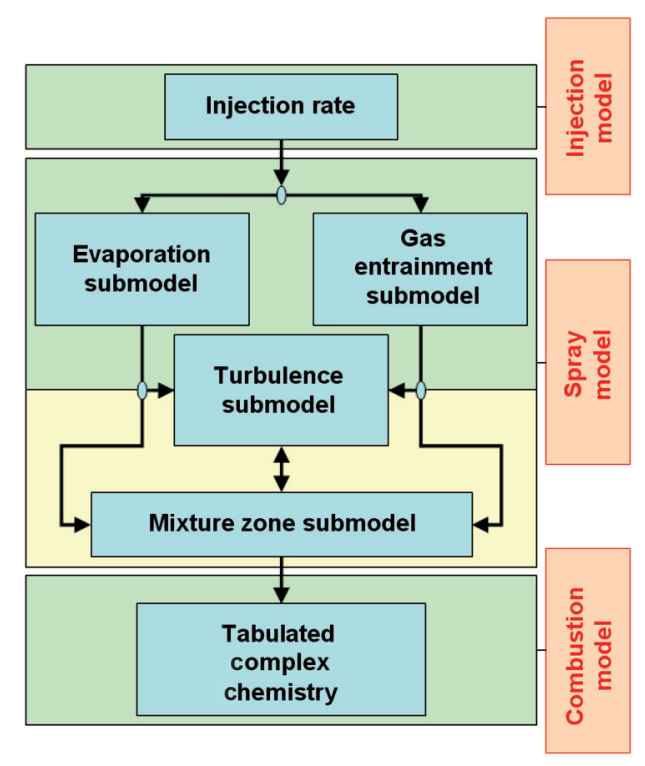

Figure 1

Synoptical diagram of the complete Diesel HCCI combustion model model is composed mainly of two parts, namely spray modelling and combustion modelling (these will be described in further detail in Sect. 2 and 3 respectively).

The purpose of spray modelling is to represent the formation and the temporal evolution of the spray volume (mixture zone), and to give constant access to the total spray mass and fuel mass-fraction distribution inside the spray. As shown in Figure 1, this model has only one input variable: the fuel injection-rate. The mixture zone has two mass sources: one is the evaporation from liquid fuel injected into the cylinder, and the other is the entrained fresh gas (in the most general case, it is a perfectly stirred mixture of air and EGR). The mixing process of gaseous fuel and fresh gas takes place in the spray volume and is controlled by turbulence. As shown in the diagram, the turbulence submodel has two inputs: one is the kinetic energy contribution associated with the injected mass of fuel and the other is the kinetic energy contribution associated with the entrained fresh gas. The mixture stratification within the spray volume is represented by a presumed PDF. The temporal evolution of the PDF shape is governed by the mass flow-rates concerning the mixture zone and the turbulence intensity. The output of the spray model is the complete spray description. It consists of quantifying the total gaseous mass contained in the mixing zone, and characterizing the fuel mass-fraction distribution inside it as well as the associated temperature field.

The goal of the combustion model is to describe the chemical composition of the mixture and the oxidation process as a function of the in-cylinder thermodynamic conditions. As shown in Figure 1, the only input required for the combustion model is the spray characterization given by the spray model. The outputs of the combustion model are the heat release and the temporal evolution of the species masses during combustion.

\section{SPRAY MODELLING}

As shown in Figure 1, the spray model contains four submodels (directional arrows indicate the different interactions):

- The evaporation submodel (Sect. 2.1): this model computes the thermodynamic conditions at the liquid-gas interface during the evaporation process, and quantifies the liquid-fuel-mass evaporation-rate. It also gives qualitative information regarding the penetration length of the liquid fuel jet.

- The gas entrainment submodel (Sect. 2.2): this model computes the entrainment of fresh air in the mixture zone. It also gives quantitative information regarding the penetration length and the volume growth of the spray.

- The turbulence submodel (Sect. 2.3): the goal of this model is to compute the characteristic frequency of the turbulence, which is directly connected with the turbulent mixing process of gaseous fuel and fresh gas (air 
and eventually EGR). As well known in ICE combustion, molecular diffusion of species is negligible compared to the turbulent one: for this reason molecular diffusion will not be considered [48].

- The mixture submodel (Sect. 2.4): the role of this model is to quantify the total mass in the mixture zone and to characterize the temporal evolution of the fuel mass fraction distribution.

\subsection{Evaporation Submodel}

The evaporation submodel has two main purposes: firstly, to compute the thermodynamic states of the fluids at the liquid-gas interface, and secondly to quantify the mass evaporation rate of the injected liquid fuel. The evaporation of droplets in a spray simultaneously involves heat and mass transfer processes. The overall rate of evaporation depends on many factors, such as pressure, temperature and transport properties of fluids, drop geometry and relative velocity of drops respective to the ambient gas. In the case of a droplet immersed in a gas at a higher temperature, part of the heat flux increases the droplet temperature, $Q_{h u}$, and the rest evaporates it. At steady-state, the droplet temperature reaches its wet-bulb value and all the heat is used for the evaporation process. When steady state conditions are established, the drop diameter, $D$, diminishes with time according to the well-established $D^{2}$ law:

$$
\frac{d D^{2}}{d t}=-\lambda
$$

where $\lambda$ is the evaporation constant.

The thermodynamic interfacial conditions are determined using the approach proposed in [49]. It describes the evaporation process, in steady-state conditions, of a single spherical liquid drop of pure fuel at rest in a gaseous mixture with a given composition, Figure 2. In such conditions, it is possible to define a mass transfer number, $B_{m}$, and a thermal transfer number, $B_{t}$, characterizing the mass and thermal boundary layers respectively, as follows:

$$
B_{m}=\frac{Y_{F_{s}}-Y_{F_{\infty}}}{1-Y_{F_{s}}} \quad \text { and } \quad B_{t}=\frac{C_{p_{g}} \cdot\left(T_{\infty}-T_{s}\right)}{L_{v_{s}}}
$$

where $Y_{F_{s}}$ and $Y_{F_{\infty}}$ are the fuel mass fractions of the mixture at the interface and ambient gas conditions respectively. $T_{s}$ and $T_{\infty}$ are the temperature of the mixture at the interface and ambient gas conditions respectively, and $L_{v_{s}}$ is the latent vaporization heat of the liquid at the interface temperature, computed using the Watson relation [50]. $C_{p_{g}}$ is the equivalent gas mixture heat-capacity at constant pressure computed using the 1/3 law proposed by Sparrow and Gregg [49]. According to this law, average properties of the mixture are evaluated at reference temperature and composition defined as:

$$
T_{1 / 3}=T_{s}+\frac{T_{\infty}-T_{s}}{3} \quad \text { and } \quad Y_{F_{1 / 3}}=Y_{F_{s}}+\frac{Y_{F_{\infty}}-Y_{F_{s}}}{3}
$$

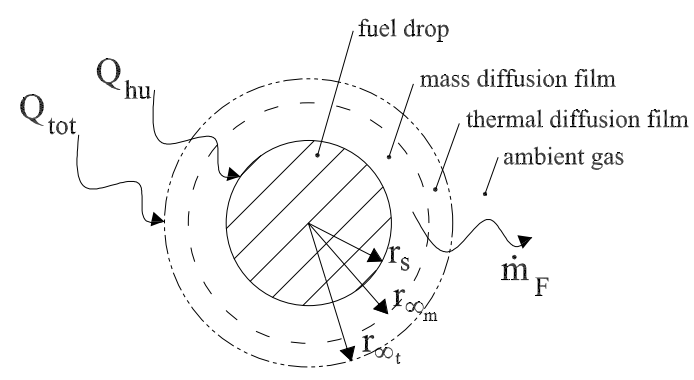

Figure 2

Evaporation model of a liquid fuel drop.

Consequently, the reference ambient-gas mass-fraction, $Y_{A_{1 / 3}}$, is given by the relation:

$$
Y_{A_{1 / 3}}=1-Y_{F_{1 / 3}}
$$

At infinite distance from the drop, fuel concentration is assumed to be zero. $C_{p_{g}}$ is then obtained as:

$$
C_{p_{g}}=Y_{A_{1 / 3}} \cdot\left(C_{p_{A}}\left(T_{1 / 3}\right)\right)+Y_{F_{1 / 3}} \cdot\left(C_{p_{F}}\left(T_{1 / 3}\right)\right)
$$

where $C_{p_{A}}$ and $C_{p_{F}}$ are the heat-capacities of the ambient gas and of the gaseous fuel respectively.

According to [49], steady-state conditions hold:

$$
B_{m}=B_{t}=B
$$

The system is solved iteratively varying the value of $T_{s}$ in order to verify Equation (6). With a maximum absolute error of $1 e^{-5}$, the number of iterations necessary to satisfy Equation (6) varies around 18. The link between the two transfer numbers is detailed as follows. At a given fuel saturation temperature at the liquid-gas interface, $T_{s}$, the fuel vapor pressure, $p_{v_{s}}$, is estimated from the ClausiusClapeyron equation as:

$$
\ln \left(p_{v_{R}}\right)=h \cdot\left(1-\frac{1}{T_{R}}\right) \quad \text { where } \quad h=T_{b_{R}} \cdot \frac{\ln \left(\frac{p_{c r}}{101325}\right)}{1-T_{b_{R}}}
$$

in which:

$$
p_{v_{R}}=\frac{p_{v_{s}}}{p_{c r}}, \quad T_{R}=\frac{T_{s}}{T_{c r}} \quad \text { and } \quad T_{b_{R}}=\frac{T_{b}}{T_{c r}}
$$

where $T_{b}$ is the normal boiling temperature of the fuel, and $p_{c r}$ and $T_{c r}$ represent its critical pressure and temperature respectively. Fuel mass fraction at the interface can now be expressed as:

$$
Y_{F_{s}}=\left[1+\left(\frac{p_{\infty}}{p_{v_{s}}}-1\right) \cdot \frac{M_{A}}{M_{F}}\right]^{-1}
$$

where $p_{\infty}$ is the ambient pressure and, $M_{A}$ and $M_{F}$ are molar masses of ambient gas and fuel respectively. 
According to [49], the fuel mass flow rate, $\dot{m}_{F}$, can be computed as:

$$
\dot{m}_{F}=2 \cdot \pi \cdot \frac{D}{L e} \cdot \frac{k_{g}}{C_{p_{g}}} \cdot \ln (1+B)
$$

and the mass of fuel, $m_{F}$, constituting a drop of given diameter is:

$$
m_{F}=\frac{\pi}{6} \cdot \rho_{F_{l}} \cdot D^{3}
$$

where $k_{g}$ is the mixture thermal conductivity, computed using the 1/3 law, Le is the Lewis number (here supposed equal to unity) and $\rho_{F_{l}}$ is the density of the liquid fuel estimated using the Hankinson-Brobst-Thomson (HBT) relation [50]. HBT relation holds to:

$$
\rho_{F_{l}}=\frac{M_{F}}{v_{s}}
$$

in which $v_{s}$ is the molar volume of the liquid at the liquid-gas interface temperature, that can be computed as:

$$
v_{s}=v_{R}^{(0)} \cdot\left[1-\Omega_{S R K} \cdot v_{R}^{(\delta)}\right] \cdot v^{*}
$$

where:

$$
\begin{gathered}
v^{*}=\frac{\mathcal{R} \cdot T_{c r}}{p_{c r}}\left(A+B \cdot \Omega_{S R K}+C \cdot \Omega_{S R K}^{2}\right) \\
v_{R}^{(0)}=1+a \cdot\left(1-T_{R}\right)^{\frac{1}{3}}+b \cdot\left(1-T_{R}\right)^{\frac{2}{3}}+c \cdot\left(1-T_{R}\right)+d \cdot\left(1-T_{R}\right)^{\frac{4}{3}} \\
v_{R}^{(\delta)}=\frac{\left[e+f \cdot T_{R}+g \cdot T_{R}^{2}+h \cdot T_{R}^{3}\right]}{T_{R}-1.00001}
\end{gathered}
$$

and $\Omega_{S R K}$ is the acentric factor of the fuel. Moreover, the constant coefficients (that are valid for all hydrocarbons) assume the following values:

$$
\begin{array}{lll}
A=0.2851686 & B=-0.0637911 & C=0.0137917 \\
a=-1.52816 & b=1.43907 & c=-0.81446 \\
d=0.190454 & e=-0.296123 & f=0.386914 \\
g=-0.0427258 & h=-0.0480645 &
\end{array}
$$

HBT correlation is valid in a temperature domain defined as:

$$
0.25<T_{R}<1.0
$$

By differentiating Equation (11) and combining it with (1) and (10), it is possible to express the evaporation constant as:

$$
\lambda=\frac{8 \cdot k_{g} \cdot \ln (1+B)}{L e \cdot C_{p_{g}} \cdot \rho_{F_{l}}}
$$

Figure 3 shows the dependence of the evaporation constant on the ambient pressure and temperature conditions for n-heptane. As shown, there is good agreement between the values computed by the model and experimental data [51].

Figure 4 shows the influence of ambient thermodynamic conditions on the mixture temperature at the liquid-gas

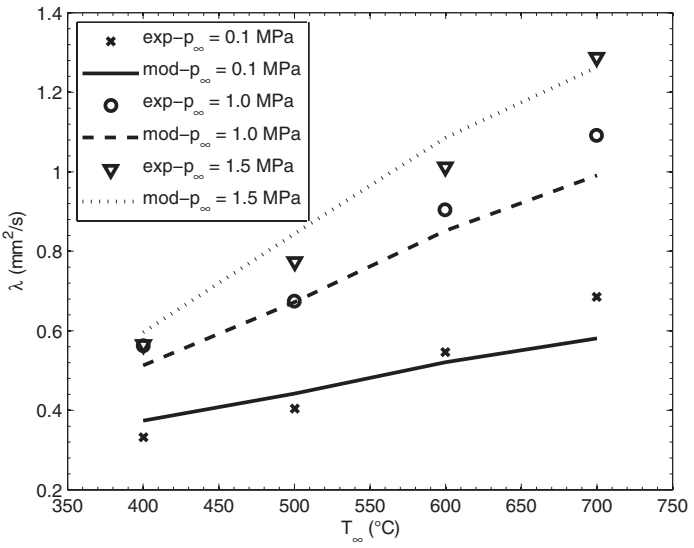

Figure 3

Dependence of the evaporation constant on the ambient conditions.

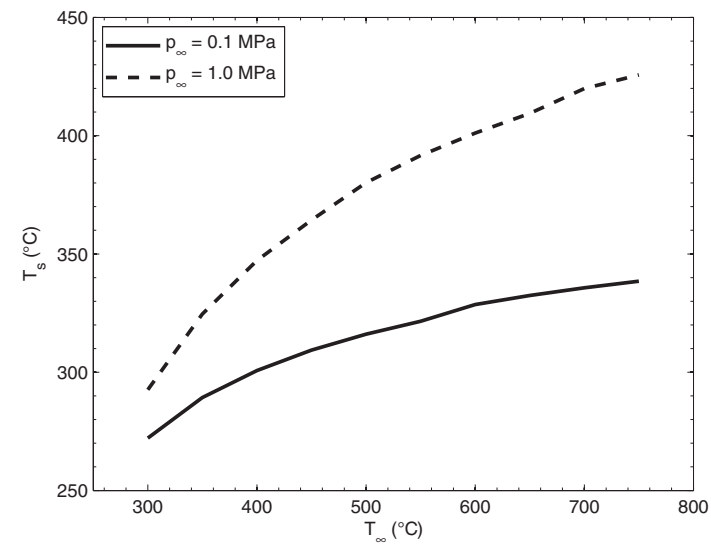

Figure 4

Dependence of the temperature at the liquid-gas interface on the ambient conditions.

interface. The computed thermochemical properties of the mixture at liquid-gas interface, such as $Y_{F_{s}}$ and $T_{s}$, will be used in the mixture characterization model and in the combustion model. These models will be presented in Sections 2.4 and 3.3 respectively. In particular, $T_{s}$ is a very important variable in the spray modelling, as it permits an estimate of the local temperature of the mixture. In what concerns the computation of the global fuel-mass evaporation-rate, several aspects must be highlighted. Equation (10) refers to single-drop evaporation. The real spray scenario is very different as droplet size distribution, ligaments and the undefined geometry of the liquid phase make it much more complicated. Consequently, because of its CPU cost, it can not be solved in a global-system simulation approach. 
For that reason, the global liquid-mass evaporation-rate has been estimated using a simpler approach, based on a characteristic time of evaporation, $\tau_{e v}$ :

$$
\dot{m}_{F}=C_{e v} \cdot \frac{m_{F_{l}}}{\tau_{e v}}
$$

where $C_{e v}$ is a dimensionless coefficient and $m_{F_{l}}$ is the liquid mass of fuel. In Section 4.1 the results of this model are compared with those of the 3D CFD code. The original method used to estimate the evaporation characteristic-time is an approach based on the theory proposed in [52,53].

This theory permits an estimate to be made of the liquid penetration length in a pressurized vessel as a function of the injector geometry, and of the compositions of the fluids and their thermodynamic states. In this approach, the spatial, $x^{+}$, and temporal, $t^{+}$, scales are defined as:

$$
x^{+}=\frac{\sqrt{C_{a}} \cdot d_{h} \cdot \sqrt{\frac{\rho_{F_{l}}}{\rho_{A}}}}{a \cdot \tan \left(\frac{\theta}{2}\right)} \text { and } t^{+}=\frac{x^{+}}{U_{F_{l}}}
$$

where $C_{a}$ is the orifice coefficient of area-contraction, $d_{h}$ is the injector hole diameter, $\rho_{A}$ is the ambient gas density, $a$ is a dimensionless coefficient (authors recommend $a=0.66$ ), $\theta$ is the opening angle of the spray (its definition will be given in Sect. 2.2), and $U_{F_{l}}$ is the fuel velocity in the injector nozzle. The theoretical expression for the maximum liquid penetration, $L$, is given as:

$$
L=\left(b \cdot \sqrt{\left(\frac{2}{B}+1\right)^{2}-1}\right) \cdot x^{+}
$$

where $b$ is a dimensionless coefficient (authors recommend $b=0.41)$ and $B$ is the transfer number computed using Equation (6).

$\tau_{e v}$ is computed by inverting the equation for the jet penetration length as a function of time and imposing a penetration length equal to $L$ [13]. That means that $\tau_{e v}$ represents the time necessary to fully evaporate a droplet whose lifetime corresponds to a penetration equal to $L$, once the velocity law is known. The expression of $\tau_{e v}$ is:

$$
\tau_{e v}=\tilde{\tau}_{e v} \cdot t^{+}
$$

where:

$$
\begin{aligned}
\tilde{\tau}_{e v}= & \frac{\tilde{L}}{2}+\frac{\tilde{L}}{4} \cdot \sqrt{1+16 \cdot \tilde{L}^{2}}+ \\
& +\frac{1}{16} \cdot \ln \left(4 \cdot \tilde{L}+\sqrt{1+16 \cdot \tilde{L}^{2}}\right)
\end{aligned}
$$

in which:

$$
\tilde{L}=\frac{L}{x^{+}}
$$

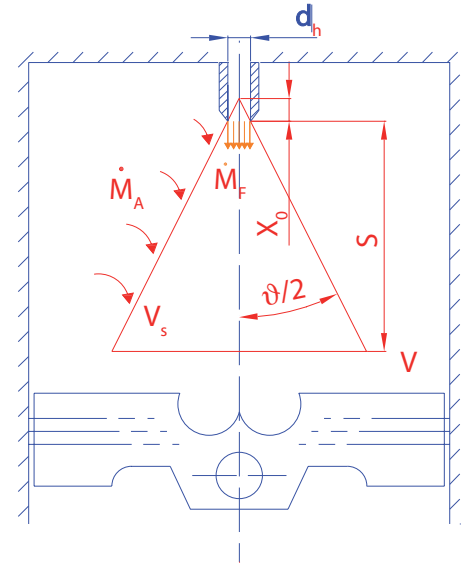

Figure 5

Spray volume description. Although the presence of two distinct volumes, the fresh-air and the spray volumes, the model is a one-zone approach. Hence, only one energy balanceequation is computed for all the in-cylinder gases.

\subsection{Gas Entrainment Submodel}

This submodel is based on the well known theory developed in [54] for estimating spray penetration and dispersion. The spray region is supposed to be a perfect truncated cone, Figure 5. Its volume, $V_{S}$, is completely defined by the height (spray penetration, $S$ ), and the angle (spray angle, $\theta$ ).

These two variables depend on the nozzle geometry, the injection pressure, and the injected and ambient fluid thermodynamic states. They are determined from the following semi-empirical correlations:

$$
S=\left[\left(\frac{1}{\frac{t_{\text {inj }}}{t^{+}}}\right)^{q}+\left(\frac{1}{\left(\frac{t_{\text {inj }}}{t^{+}}\right)^{\frac{1}{2}}}\right)^{q}\right]^{-\frac{1}{q}} \cdot x^{+}
$$

and:

$$
\tan \left(\frac{\theta}{2}\right)=C_{\theta} \cdot\left[\left(\frac{\rho_{A}}{\rho_{F_{l}}}\right)^{0.19}-0.0043 \cdot \sqrt{\frac{\rho_{F_{l}}}{\rho_{A}}}\right]
$$

where $q$ is a dimensionless coefficient (authors recommend $q=2.2$ ), $t_{i n j}$ is the relative time coordinate, with origin at the beginning of the injection, and $C_{\theta}$ is a constant coefficient. Hence:

$$
V_{S}=\frac{\pi}{3} \cdot \tan ^{2}\left(\frac{\theta}{2}\right) \cdot\left[\left(S+x_{0}\right)^{3}-x_{0}^{3}\right]
$$

with $x_{0}$ defined in Figure 5.

Through experimentation of injection in a constant volume vessel containing a gas at a given pressure and temperature, these correlations have been widely validated. Results are reported in various works by different authors $[20,42,54,55]$. 


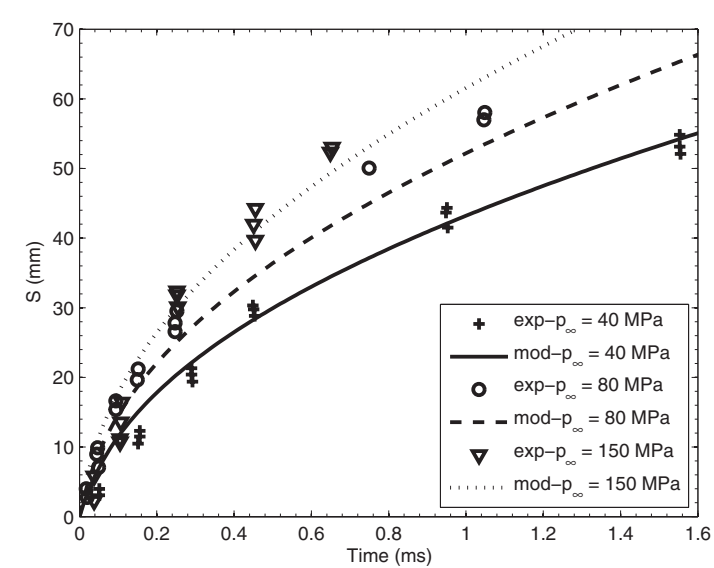

Figure 6

Vapor phase penetration. n-heptane, $T_{\infty}=387 \mathrm{~K}, \rho_{A}=25 \mathrm{~kg} / \mathrm{m}^{3}$.

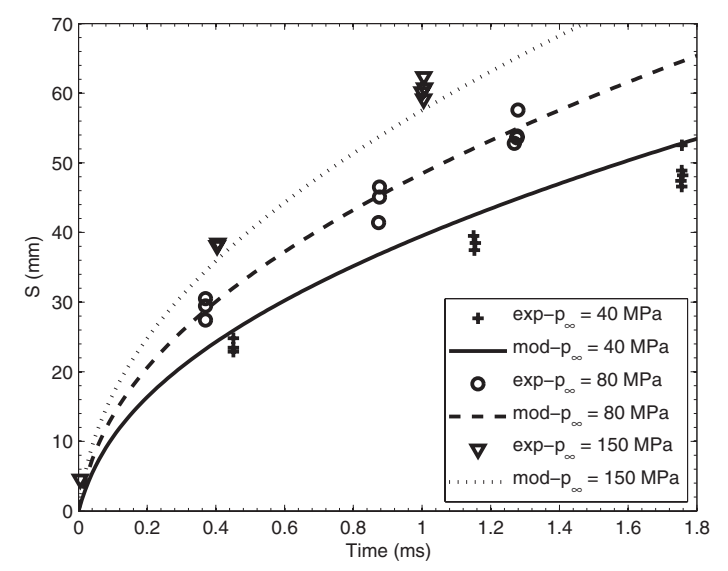

Figure 7

Vapor phase penetration.

n-heptane, $T_{\infty}=800 \mathrm{~K}, \rho_{A}=30 \mathrm{~kg} / \mathrm{m}^{3}$.

Figures 6 and 7 compare the computed spray penetrations with experimental data obtained in a high pressure vessel [42]. The results are in good agreement with experiments. As can be seen, the model is sensitive to the variation of parameters such as injection pressure, nozzle geometry and the thermodynamic state of the ambient gas.

In ICE conditions, in-cylinder thermodynamic conditions vary in time because of the piston motion, thermal exchanges and combustion process. In order to take into account the time history of spray penetration, the differential form of Equation (27) has been implemented in the model. Consequently, the spray volume is computed as:

$$
V_{S}=\int \dot{V}_{S} \cdot d t
$$

The mass of entrained gas in the spray volume is deduced from geometrical considerations:

$$
\frac{d m_{A}}{d t}=\rho_{A} \cdot \frac{d V_{S}}{d t}
$$

where $d m_{A} / d t$ is the entrained mass-flow-rate and $\rho_{A}$ is the density of the gas still outside the spray region.

\subsection{Turbulence Submodel}

In ICE, turbulence plays a very important role, increasing mass, momentum and energy transfer-rates. The dynamics of turbulent motion can be described as follows. At first, kinetic energy associated with the mean flow is transferred to the large scales of the fluctuating motion (integral scale). After that, kinetic energy is transferred isentropically from large to small scales of turbulence (Kolmogorov scale). Finally, the kinetic energy is dissipated by viscous forces and is transformed into thermal energy. The aim of the turbulence submodel is to obtain an estimate of the turbulence characteristic time, $\tau_{t}$, which is very important in the mixing process modelling.

The proposed approach is based on the well-known $\kappa-\epsilon$ turbulence-model theory. According to this theory, the kinetic energy is decomposed into two contributions:

- the mean kinetic energy, associated to the big structures of the mixture flow,

- the turbulent kinetic energy, associated to the local mixture velocity-fluctuations respect to the mean value.

The procedure to estimate $\tau_{t}$ is detailed in the following.

The turbulence submodel constitutes of two state variables: the spray global kinetic-energy, $E_{c}$, and the mean specific kinetic-energy, $\tilde{K}^{(1)}$.

\subsubsection{Spray Global Kinetic-Energy}

The spray global kinetic-energy rate can be most generally expressed as the sum of a production and a dissipation term:

$$
\frac{d E_{c}}{d t}=\left.\frac{d E_{c}}{d t}\right|_{p r}+\left.\frac{d E_{c}}{d t}\right|_{d s}
$$

The production term in an ICE application can be detailed as follows:

$$
\left.\frac{d E_{c}}{d t}\right|_{p r}=\frac{d E_{c_{\text {swirl }}}}{d t}+\frac{d E_{c_{\text {tumble }}}}{d t}+\frac{d E_{c_{\text {squish }}}}{d t}+\frac{d E_{c_{S}}}{d t}
$$

The spray energy, $E_{c_{S}}$, represents $98 \%$ of the total kinetic energy, according to [20]. For that reason, with good approximation, it is possible to affirm that:

$$
\left.\frac{d E_{c}}{d t}\right|_{p r} \approx \frac{d E_{c_{S}}}{d t}=\frac{U_{F_{l}}^{2}}{2} \cdot \frac{d m_{F_{i n j}}}{d t}
$$

(1) The symbol tilde means that the mean kinetic energy value has been computed using the Favre mean operator. 
in which:

$$
U_{F_{l}}=\frac{1}{C_{d} \cdot n_{h} \cdot \rho_{F_{l}} \cdot\left(\frac{\pi}{4} \cdot d_{h}^{2}\right)} \cdot \frac{d m_{F_{\text {inj }}}}{d t}
$$

where $m_{F_{i n j}}$ is the mass of injected fuel, $C_{d}$ is the discharge coefficient of the orifice and $n_{h}$ is the number of holes of the nozzle.

The spray global kinetic-energy dissipation-term, mainly due to flow viscous forces, has been modeled by using empirical closure terms [13].

Equation (30) can now be rewritten as:

$$
\frac{d E_{c}}{d t}=\frac{U_{F_{l}}^{2}}{2} \cdot \frac{d m_{F_{i n j}}}{d t}-m_{S} \cdot\left(C_{K} \cdot \tilde{K}^{N_{K}}+C_{\kappa} \cdot \tilde{\kappa}^{N_{\kappa}}\right)
$$

where $m_{S}$ is the total mass of the spray, $C_{K}$ and $N_{K}$ are empirical dissipation-term constant-coefficients associated to the mean specific kinetic-energy, $\tilde{K}$, and $C_{K}$ and $N_{K}$ are empirical dissipation-term constant-coefficients associated to the mean specific turbulent kinetic-energy, $\tilde{\kappa}$.

\subsubsection{Mean Specific Kinetic-Energy}

Similarly to $\kappa-\epsilon$ theory, by spatially filtering the 3D momentum balance-equation, it is possible to obtain an expression for the temporal evolution of the mean specific kinetic-energy [13]:

$$
\begin{aligned}
\frac{d \tilde{K}}{d t}= & \frac{\sqrt{2 \cdot \tilde{K}}}{m_{S}} \cdot\left[U_{F_{l}} \cdot \frac{d m_{F_{i n j}}}{d t}-\sqrt{2 \cdot \tilde{K}}\right. \\
& \left.\cdot\left(\frac{d m_{A}}{d t}+\frac{d m_{F_{i n j}}}{d t}\right)\right]-C_{K} \cdot \tilde{K}^{N_{K}}
\end{aligned}
$$

where, as can be seen, the last right-hand-side term represents the mean specific kinetic-energy dissipation-term, already present in Equation (34). The filter size used to obtain Equation (35) is the spray volume, $V_{S}$.

\subsubsection{Characteristic time of turbulence}

It is now possible to compute the mean specific turbulent kinetic-energy value as:

$$
\tilde{\kappa}=\frac{E_{c}}{m_{S}}-\tilde{K}
$$

The term indicating the mean specific turbulent-kineticenergy dissipation-rate, $\tilde{\epsilon}$, is supposed to have an expression similar to the one used to represent the dissipation rate of the mean specific kinetic-energy:

$$
\tilde{\epsilon}=C_{\kappa} \cdot \tilde{K}^{N_{K}}
$$

as shown in Equation (34).
According to the $\kappa-\epsilon$ turbulent model theory, the characteristic time associated to turbulence is defined as:

$$
\tau_{t}=\frac{\tilde{\kappa}}{\tilde{\epsilon}}
$$

The proposed OD turbulence model, derived from the 3D approach, has the advantage of describing well the mechanism involving the transfer of kinetic energy in the frequency domain from large to small scales of turbulence due to the shear forces. Results concerning the turbulence submodel will be discussed in Section 4.1.

\subsection{Mixture Submodel}

One of the main issues in Diesel HCCI combustion modelling is that auto-ignition and combustion processes take place in stratified-mixture conditions. In order to define a model able to predict both these phenomena, the modelling of the mixture stratification is of primary importance. To improve this aspect in the model, one solution is to use a presumed PDF approach, commonly used in 3D codes, which describes the mixture stratification using a statistical tool. A PDF is then used to estimate several local variables, such as mixture composition, temperature or reaction rates. Moreover, using the PDF approach implies the addition of only one more state variable and, as a results, a minimum impact on the differential equation system size and consequently on the CPU time cost.

\subsubsection{Mixture Fraction Variable}

According to the theory developed to study the laminar diffusion flame [48], combining the transport equations of fuel mass fraction, $Y_{F}$, and oxidizer mass fraction, $Y_{O}$, it is possible to define a combustion-independent scalar (SchwabZeldovitch variable), $\varphi$, as:

$$
\varphi=Y_{F}-\frac{Y_{O}}{s}
$$

where $s$, the mass stoichiometric coefficient, is defined as:

$$
s=\frac{v_{O}}{v_{F}} \cdot \frac{M_{O}}{M_{F}}
$$

Here, $v_{i}$ represents the molar coefficient of the stoichiometric combustion reaction and $M_{i}$ is the species molar weight.

The normalization of the variable $\varphi$ with the mass fractions relative to the fuel and oxidizer streams gives the mixture fraction variable, $Z$, whose values through the diffusive layer vary between 0 , in pure oxidizer, and 1 , in pure fuel. $Z$ can be expressed as:

$$
Z=\frac{\Phi \cdot \frac{Y_{F}}{Y_{F_{0}}}-\frac{Y_{O}}{Y_{O_{0}}}+1}{\Phi+1}
$$


where $Y_{F_{0}}$ is the fuel mass fraction in the fuel feeding stream and $Y_{O_{0}}$ is the oxydizer mass fraction in the oxydizer stream. $\Phi$ is the equivalence ratio of the nonpremixed flame defined as:

$$
\Phi=\frac{Y_{F_{0}}}{Y_{O_{0}}} \cdot s
$$

It is possible to demonstrate that:

$$
Z=Y_{F_{\tau}}
$$

where $Y_{F_{\tau}}$ is the fuel-tracer mass-fraction, that is the local fuel mass-fraction in the case of a non-reactive mixture.

\subsubsection{Presumed PDF}

Different kinds of PDF are available in the literature. In order to simulate the mixing process taking place in diffusion flames, the PDF described by a $\beta$-function has been judged the best adapted [56]. A $\beta$-PDF function is a normalized statistical tool representing the probability, $\mathcal{P}\left(X^{*}\right)$, of a generic variable $X$, defined in its own domain of existence $(0 \leq X \leq 1)$.

A $\beta$-PDF is completely described by two parameters. The first one is the mean value of the distribution, $\bar{X}$, defined as:

$$
\bar{X}=\int_{0}^{1} X^{*} \cdot \mathcal{P}\left(X^{*}\right) \cdot d X^{*}
$$

and the second is the segregation factor of the distribution, $\delta$, defined as:

$$
\delta=\frac{\overline{X^{\prime 2}}}{\overline{X^{\prime 2}} \max }
$$

where $\overline{X^{\prime 2}}$ is the value of the variance of the distribution computed as:

$$
\overline{X^{\prime 2}}=\int_{0}^{1}\left(X^{*}-\bar{X}\right)^{2} \cdot \mathcal{P}\left(X^{*}\right) \cdot d X^{*}
$$

and $\overline{X^{\prime 2}}$ max is the maximum value of the variance defined as:

$$
\overline{X^{\prime 2}} \max =\bar{X} \cdot(1-\bar{X})
$$

The mathematical expression of $\mathcal{P}(X)$ is:

$$
\mathcal{P}\left(X^{*}\right)=\frac{\Gamma(\alpha+\beta)}{\Gamma(\alpha) \cdot \Gamma(\beta)} \cdot X^{*^{\alpha-1}} \cdot\left(1-X^{*}\right)^{\beta-1}
$$

with:

$$
\Gamma(a)=\int_{0}^{+\infty} e^{-t} \cdot t^{a-1} \cdot d t
$$

and the coefficients $\alpha$ and $\beta$ are defined as:

$$
\alpha=\bar{X} \cdot\left[\frac{1}{\delta}-1\right] \quad \text { and } \quad \beta=\frac{1}{\bar{X}}-\alpha
$$

Figure 8 shows the typical evolution of the $\beta$-PDF.

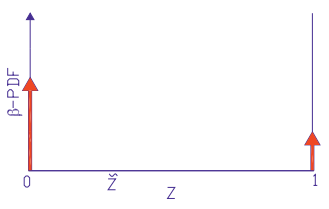

(a)

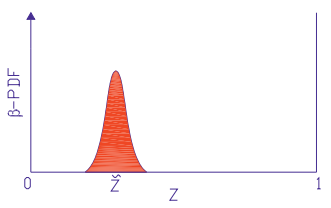

(c)

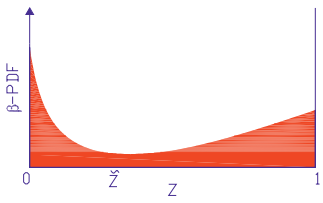

(b)

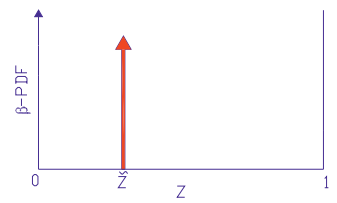

(d)
Figure 8

Representation of $\beta-P D F$ evolution. At the beginning representing a perfectly unmixed mixture (a); at an intermediary stage still presenting two peaks of mixture fraction (b); at an intermediary stage presenting one peak of mixture fraction (c); and at the end of the mixing process a perfectly stirred mixture (d).

The studied configuration is representative of the mixing process taking place in a closed constant volume initially containing pure fuel and oxidizer. The value of $\tilde{Z}$ is constant in time once the mass proportion of the two gases is fixed. $\tilde{Z}$ can be computed as:

$$
\tilde{Z}=\frac{m_{F}}{m_{F}+m_{O}}
$$

At $t=0$, the oxidizer and fuel are perfectly unmixed $(\delta=1)$. In this case, $\beta$-PDF presents two peaks: one representing the pure oxidizer (at $Z=0$ ), and the other representing the pure fuel (at $Z=1$ ). At times $t_{1}$ and $t_{2}$, two intermediary configurations are presented. The mixing process is going on so consequently $\delta$ decreases; $\beta$-PDF is a continuous curve. At $t=t_{\text {end }}$, the mixture is perfectly stirred, and in this case, $\beta$-PDF presents one peak centered at $\tilde{Z}$.

\subsubsection{Application of the Submodel to ICE}

As shown in the previous paragraph, $\beta$-PDF is a tool potentially adapted to reproduce the mixture stratification evolution during a mixing process. The last step in completing the mixture model is to determine the equations giving the temporal evolution of these two parameters defining the PDF (and so of the mixture stratification). For the sake of clarity, it is important to remember that the mixture submodel details the gas mixture composition inside the spray volume. 
Compared with the previous example, referred to two perfectly-unmixed gases in a closed constant-volume, the ICE application is much more complicated:

- both volume and total mass grow in time,

- the upper limit of the mixture-fraction existence-domain, $Z_{s}$, that corresponds to the value $Y_{F_{s}}$ computed by the evaporation submodel, evolves in time as a function of the in-cylinder thermodynamic conditions,

- the fuel/ambient gas ratio, and so likewise the mean value of the mixture fraction, varies in time.

\section{Distribution Mean Value Equation}

The mean value is computed as the ratio of the total fuelevaporated mass, $m_{F}$, and the total mass of gas in the spray volume, $m_{S}$ :

$$
\tilde{Z}=\frac{m_{F}}{m_{S}}=\frac{m_{F}}{m_{F}+m_{A}}
$$

$m_{F}$ and $m_{A}$ are obtained by integration of the evaporation and entrainment gas submodel-outputs respectively, Figure 1.

\section{Distribution Variance Equation}

By definition, the variance of the distribution of $Z$ in the spray is:

$$
\widetilde{Z^{\prime \prime 2}}=\frac{1}{m_{S}} \cdot \int_{m_{S}}\left(\left.Z\right|_{d m}-\tilde{Z}\right)^{2} \cdot d m
$$

Differentiating this expression ${ }^{(2)}[13]$ :

$$
\begin{aligned}
& \frac{d \widetilde{Z^{\prime \prime 2}}}{d t}=-\underbrace{2 \cdot C_{d i s s} \cdot \frac{\widetilde{Z^{\prime 2}}}{\frac{\tilde{K}}{\tilde{\epsilon}}}}_{I}+\underbrace{\frac{1}{m_{S}} \cdot\left(\tilde{Z}^{2}-\widetilde{Z^{\prime \prime 2}}\right) \cdot \frac{d m_{A}}{d t}}_{I I}+ \\
& +\underbrace{\frac{1}{m_{S}} \cdot\left(\tilde{Z}^{2} \cdot\left(1-\frac{1}{Z_{s}}\right)+\left(Z_{s}-\tilde{Z}\right)^{2} \cdot \frac{1}{Z_{s}}-\widetilde{Z^{\prime \prime 2}}\right) \cdot \frac{d m_{F}}{d t}}_{I I I}
\end{aligned}
$$

The use of the $\beta$-function to represent the PDF, as already seen, brings several positive aspects, but also imposes some limitations on the mixture-distribution description. For example, Figure 9 shows a situation that cannot be represented by a $\beta$-function. To reduce the impact of these limitations on modelling, in the following the upper limit of the distribution domain will be considered as constant and equal to the maximum value reached during the evaporation process, $Z_{s_{\max }}$.

In Equation (54), it is possible to distinguish three contributions. The first term, $I$, corresponds to the mixing-process contribution (term of dissipation of the variance). It is only thought to depend on turbulence and it is proportional to the turbulence characteristic-frequency via the $C_{\text {diss }}$ coefficient.

(2) Complete proof of Equation (54) is given in Appendix.

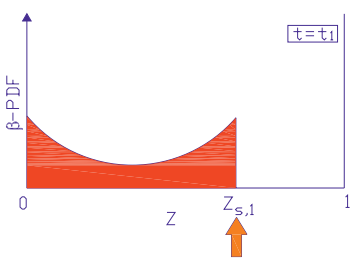

(a)

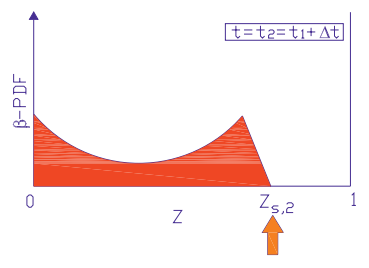

(b)

\section{Figure 9}

Representation of $\beta-P D F$ limitation: mixture fraction distribution at the instant $t=t_{1}$ (a), mixture fraction distribution at the instant $t=t_{2}=t_{1}+\Delta t$ (b). During $\Delta t$ temperature increases and liquid fuel evaporates at $Z=Z_{s, 2}$.

The second term, $I I$, corresponds to the entrained ambientgas contribution. The last term, III, corresponds to the fuelevaporation contribution. In this term, it has been done on the assumption that liquid fuel evaporates at saturated thermodynamic conditions in pure ambient gas.

\section{$\beta$-PDF Parameters}

Once the mean value and the variance of the mass fraction distribution have been computed, they have to be normalized in order to be adapted for use with a presumed PDF.

The proposed normalization takes into account the fact that $Z_{s_{\max }}$ can be smaller than unity. Mean value and variance are respectively normalized as follows:

$$
\tilde{Z}_{\beta-P D F}=\frac{\tilde{Z}}{Z_{s_{\max }}}
$$

and:

$$
\delta_{\beta-P D F}=\frac{\widetilde{Z^{\prime 2}}}{\widetilde{Z^{\prime \prime 2}} \max }=\frac{\widetilde{Z " 2}}{\tilde{Z} \cdot\left(Z_{s_{\max }}-\tilde{Z}\right)}
$$

The evaporation of the liquid fuel in the cylinder, especially during combustion, takes place under transcritical or supercritical conditions $[57,58]$. The evaporation approach proposed in this work is not adapted to describe the evaporation process under these conditions, for the following reasons:

- the perfect gas hypothesis is no longer valid,

- Clapeyron's law is not valid,

- the ambient-gas dissolution in liquid is no longer negligible,

- the concept of a liquid-gas interface vanishes.

According to [57, 59], using a subcritical evaporation model instead of a tran/super-critical one leads to an underestimation of the value of the maximum fuel mass-fraction. For these reasons the maximum value of fuel mass-fraction 


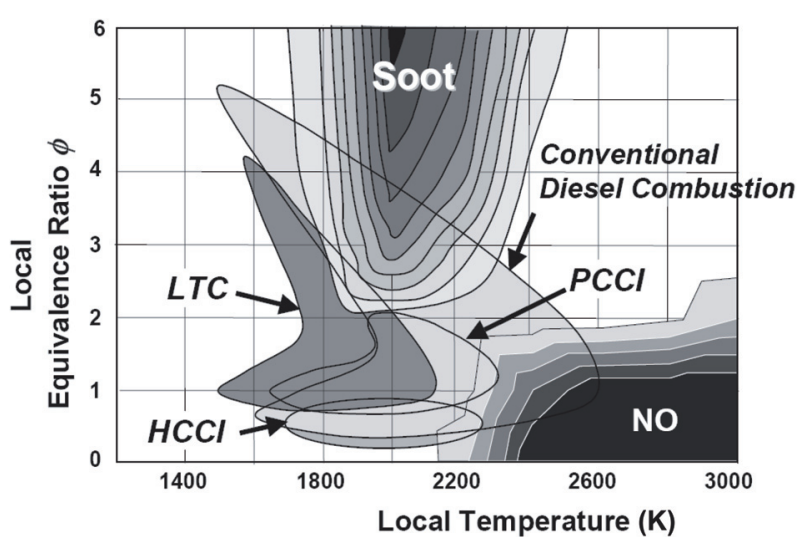

Figure 10

PCCI, LTC and HCCI concept on a $\Phi-T$ map [60].

has been arbitrarily imposed as equal to unity. This assumption will be partially justified in the following by showing the good agreement between the evolutions of the fuel mixture-fraction distributions computed by the $0 \mathrm{D}$ and 3D models, Section 4.1.

\section{COMBUSTION MODELLING}

\subsection{Complex Chemistry Approach Motivation}

The second part of the Diesel HCCI combustion model, Figure 1, concerns the modelling of the combustion process. Due to the limitations on pollutant emissions, a deeper understanding on the pollutant formation mechanisms must be achieved. The introduction of non-conventional combustion regimes is seen as a possible key point.

This is the case for PCCI (Premixed Controlled Compression Ignition), LTC (Low Temperature Combustion) and HCCI combustions, Figure 10 [60]. As shown, the tendency is to obtain a combustion process characterized by lower temperatures and a higher level of local air-excess ratio, in order to get off the region relative to $\mathrm{NO}_{\mathrm{x}}$ and soot emissions. Nowadays, to reduce the combustion temperatures, it is usual to dilute the fuel-air mixture with EGR because of its high specific heat-capacity and immediate availability. The EGR dilution effect has a direct impact on the chemical kinetics of combustion. In particular, it slows the formation process of active radicals of combustion and reduces their local concentration. It is common, by using high EGR rates, to split the heat release process into two stages: the first, called cold flame, associated to the fuel decomposition in intermediary species; and the second, called main flame, associated to the oxidation process.

To predict all of these scenarios, a complex chemistry approach is required. Figure 11 shows the temperature evolutions relative to two examples of combustion processes

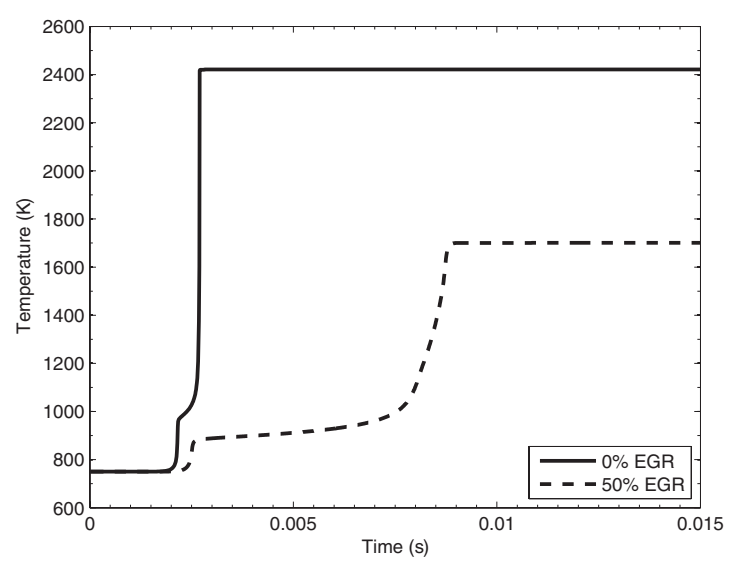

Figure 11

Results from SENKIN for EGR rate influence on auto-ignition of a perfectly stirred mixture of $n$-heptane/air/EGR in a constant volume reactor. Initial states: $T_{0}=750 \mathrm{~K}, p_{0}=25$ bar, $\Phi=0.6$, and $X_{r}=0 \%$ and $50 \%$ for solid and dashed lines respectively.

performed with SENKIN from CHEMKIN [61]. Both configurations are relative to the combustion of a homogeneous fuel/air mixture in an adiabatic constant-volume reactor. Initial conditions do not change between the two configurations, except for the EGR dilution rate. Nevertheless, in the configuration with a higher EGR rate, it is possible to clearly distinguish the two-step auto-ignition process and the reduction of the final combustion temperature.

\subsection{Tabulation Methodology}

Commercial Diesel fuel is not a pure hydrocarbon but a mixture of many different ones; moreover, a univocal definition of Diesel fuel does not exist. Nevertheless the mixture, in order to be commercialized as Diesel fuel, must respect rigorous specifications.

A Diesel fuel-surrogate is often adopted in combustion modelling. It is usually a pure fuel that presents the same auto-ignition properties as the real fuel. For this paper nheptane has been chosen as the Diesel fuel substitute.

In literature several complex chemical kinetics schemes exist for n-heptane. Here, the complete scheme proposed in [62] involving 544 species and 2446 reactions has been chosen. In a OD model dedicated to a global-system simulation context, in which the CPU computation-cost is a first order evaluation parameter, it is an unreasonable choice to solve the complete chemical scheme. Hence a tabulated chemistry method, inspired by 3D approaches [45], has been set up.

In 1992, [63, 64] have demonstrated the existence of attractive trajectories, in the chemical phase space. Based on this, they proposed a theory to simplify the chemical kinetics description, namely the ILDM method. In 2000, 
[47] proposed to extend this theory by prolonging trajectories with premixed laminar-flame computations: the FPI method. In 2004, [65] replaced premixed laminar flames with auto-ignition flames, and obtained good results on autoignition prediction.

To establish the look-up table, it is necessary to define the main species involved in the chemical scheme. The choice of these species is crucial, because their evolutions have to be sufficient to represent the whole chemical scheme. Here, 8 major species have been identified from mass and energy considerations: $\mathrm{C}_{7} \mathrm{H}_{16}, \mathrm{~N}_{2}, \mathrm{O}_{2}, \mathrm{H}_{2} \mathrm{O}, \mathrm{CO}_{2}, \mathrm{CO}, \mathrm{H}_{2}$ and $\mathrm{H}$ [20].

The thermochemical state of the gaseous mixture of fuel, air and EGR can be completely described with the following four parameters:

- $p_{0}$ : pressure,

- $T_{0}$ : temperature,

- $\Phi$ : equivalence ratio,

- $X_{r}$ : molar EGR rate in ambient gas. It is defined as:

$$
X_{r}=1-\frac{4.76 \cdot X_{\mathrm{O}_{2}}}{1-X_{F}}
$$

where $X_{\mathrm{O}_{2}}$ and $X_{F}$ are the oxygen and fuel molarfractions respectively.

They constitute an orthogonal base in the phase space, and they have been chosen as inputs of the table. In order to describe the progress of the combustion process, a fifth parameter representing the progress variable, $c$, is necessary.

The progress variable must satisfy the following properties:

- $c$ varies in a closed interval between 0 and 1: 0 in the fresh gases and 1 in the burnt gases,

- $c$ must be monotonic with the progress of combustion,

- $c$ must be representative of all main reactions.

The generic definition of $c$ used in a FPI approach is:

$$
c=\frac{Y_{l c}(t)-Y_{l c}(t=0)}{Y_{l c}\left(t_{e q}\right)-Y_{l c}(t=0)}
$$

with the mass fraction linear combination, $Y_{l c}$, expressed as:

$$
Y_{l c}=\sum_{e s p=1}^{N} \sigma_{e s p} \cdot Y_{e s p}
$$

where $t_{e q}$ stands for the time necessary to reach the chemical equilibrium, $\sigma_{e s p}$ is a coefficient depending on the species and $N$ is the number of species.

According to [13], in the model, $Y$ has been defined as:

$$
Y_{l c}(t)=-Y_{\mathrm{O}_{2}}(t)+Y_{\mathrm{CO}}(t)+Y_{\mathrm{CO}_{2}}(t)
$$

The reaction rate associated with a given species is expressed as:

$$
\omega_{e s p}=\omega_{e s p}\left(p_{0}, T_{0}, \Phi, X_{r}, c\right)
$$

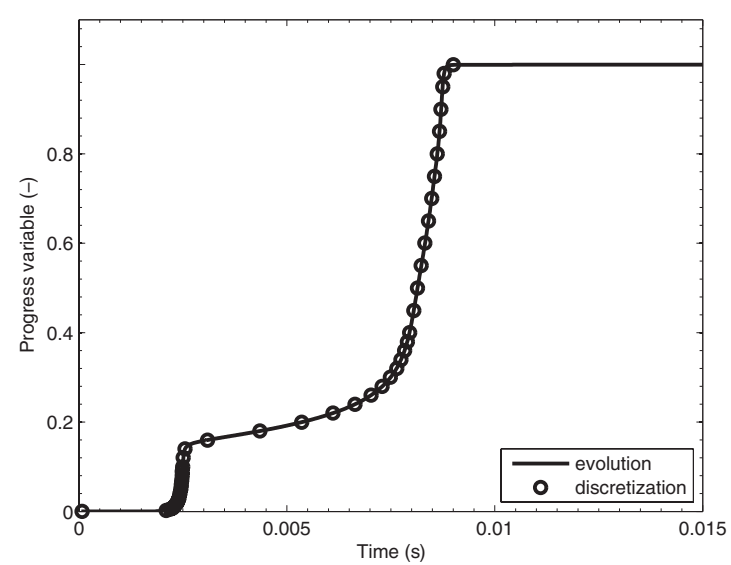

Figure 12

Progress variable discretization. The curve refers to the combustion process of a perfectly stirred mixture of $n$ heptane/air/EGR in a constant volume reactor. Initial state: $T_{0}=750 \mathrm{~K}, p_{0}=25$ bar, $\Phi=0.6$, and $X_{r}=50 \%$.

All the criteria necessary to set up the table are now defined. It remains to define the limits and the discretization of the look-up table domain. They are chosen in order to obtain the best compromise between accuracy and table size. In the model, the following choices have been made:

- 8 initial pressure values chosen in the interval between 10 bar and 90 bar,

- 54 initial temperature values chosen in the interval between $600 \mathrm{~K}$ and $1600 \mathrm{~K}$,

- 6 equivalence ratio values chosen in the interval between 0.3 and 3 ,

- 5 molar EGR rate values chosen in the interval between $0 \%$ and $90 \%$,

These correspond to an initial condition map of 12960 operating points. The combustion process computation using SENKIN is then performed at each operating point, considering a perfectly stirred constant-volume reactor and adopting the complete chemical kinetics scheme. From each simulation the evolution of the progress variable is determined and discretized in 44 points (fifth table input). Finally, the table is filled up with the reaction rates of each tabulated species. Figure 12 shows the discretization of the temporal progress variable evolution.

Among the eight major species retained, only four have been tabulated: $\mathrm{O}_{2}, \mathrm{CO}, \mathrm{CO}_{2}$ and $\mathrm{H}$. The others are determined using $\mathrm{C}, \mathrm{O}, \mathrm{H}$ and $\mathrm{N}$ atomic balance equations. For example the carbon atomic balance equation is:

$$
\frac{d}{d t}\left(7 \cdot X_{\mathrm{C}_{7} \mathrm{H}_{16}}+X_{\mathrm{CO}_{2}}+X_{\mathrm{CO}}\right)=0
$$

This tabulation method for $\mathrm{n}$-heptane has been validated and widely discussed [13]. 


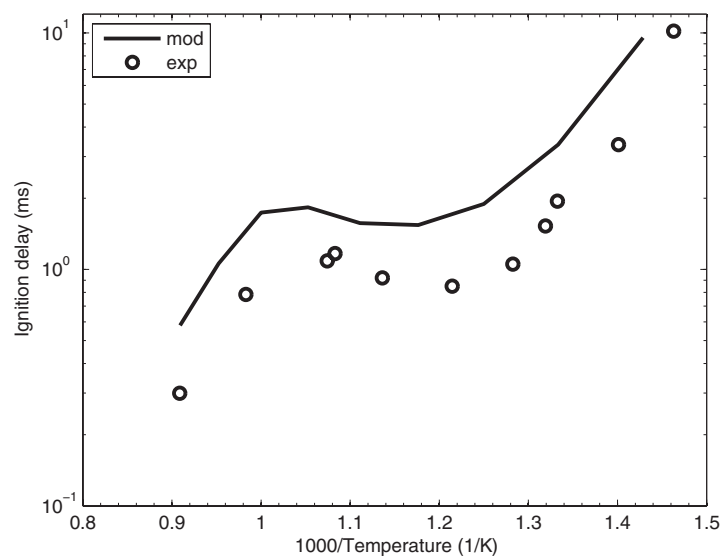

Figure 13

Dependence of the main ignition-delay on the temperature for a perfectly stirred mixture of $n$-heptane/air in a constant pressure reactor. SENKIN results are compared with experimental data. Initial state: $p_{0}=42$ bar, $\Phi=0.5$.

For the sake of clarity, and in order to show the potential of using a complex chemistry approach, some results are reported below.

Figure 13 shows the evolution of the main combustion ignition-delay for a given mixture at a given initial pressure as a function of initial temperature. Values computed using SENKIN are plotted against experimental data [66]. The ignition delays are determined from the maximum temperature gradient. It is interesting to note the NTC (Negative Temperature Coefficient) zone in the interval of temperature from $850 \mathrm{~K}$ to $950 \mathrm{~K}$. In that interval, an augmentation of the initial temperature corresponds to an augmentation of the ignition delay. Figure 14 shows the evolutions of four major species $\left(\mathrm{C}_{7} \mathrm{H}_{16}, \mathrm{O}_{2}, \mathrm{CO}_{2}\right.$ and $\left.\mathrm{CO}\right)$ during the combustion process. Results computed using the tabulated chemistry and the complete chemical scheme (SENKIN) are compared. It concerns an homogeneous lean-mixture with $50 \%$ of EGR. It is worth pointing out two aspects:

- the species evolution is well predicted if the species is a tabulated one (e.g. $\left.\mathrm{CO}_{2}\right)$. This is not the case for $\mathrm{n}$ heptane as it is a reconstructed species that includes all carbonate species other than $\mathrm{CO}_{2}$ and $\mathrm{CO}$,

- potentially, the tabulated-chemistry method allows for the description of any species evolution during combustion. Concerning the study of pollutant emissions, this is a very interesting aspect (e.g. it allows for the determination of thermochemical conditions that favor pollutant formation).
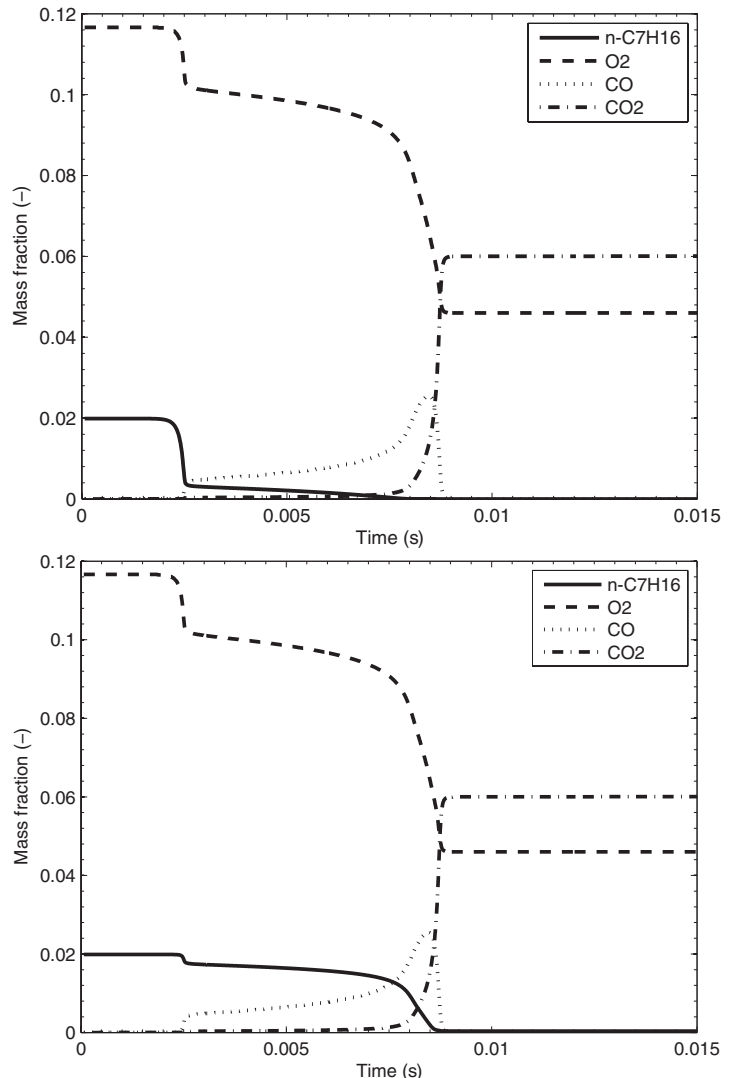

Figure 14

Evolution of several species during combustion. Comparison between complete chemical scheme (top) and tabulated chemical scheme (bottom). The difference between reconstructed (tabulation method) and computed (complex chemistry method) evolutions concerning the n-heptane is put in evidence. Curves refer to the combustion process of a perfectly stirred mixture of $n$-heptane/air/EGR in a constant volume reactor. Initial state: $T_{0}=750 \mathrm{~K}, p_{0}=25 \mathrm{bar}, \Phi=0.6$, and $X_{r}=50 \%$.

\subsection{Matching of Spray and Combustion Models}

The last step in obtaining the global Diesel HCCI combustion model, Figure 1, consists of matching the spray model with the combustion model.

First of all, it is important to define the relation between the fuel mass-fraction, $Z$, used to characterize the mixture stratification in $\beta$-PDF and the equivalence ratio, $\phi$, representing an input variable of the look-up table:

$$
Z=\frac{\Phi}{P C O} \cdot\left(1-X_{r} \cdot \frac{M_{r}}{M_{m i x}}\right) \cdot \frac{1}{\frac{\Phi}{P C O}+1}
$$

with:

$$
\Phi=\frac{Y_{F}}{Y_{\mathrm{O}_{2}}} \cdot s \quad \text { and } \quad P C O=\frac{m_{a}}{m_{F}}
$$


where $M_{r}$ and $M_{m i x}$ are the molar masses of the EGR and of the mixture respectively, and $m_{a}$ is the mass of air necessary to burn the fuel in stoichiometric conditions. As shown in Equation (63), $Z$ is a function of two look-up table inputs. Therefore particular attention must be paid in interpolating the table values. In the presented ICE application, the initial values of pressure and temperature, $p_{0}$ and $T_{0}$ respectively, correspond to the in-cylinder pressure and temperature conditions associated with the non-reactive engine-cycle simulation:

$$
p_{0}=p_{\tau} \quad \text { and } \quad T_{0}=T_{\tau}
$$

The most general form of the equation used to compute the mean reaction rate in a stratified mixture associated to a tabulated species is:

$$
\bar{\omega}_{e s p}=\int \omega \cdot \mathcal{P}_{c o} \cdot d p_{\tau}^{*} \cdot d T_{\tau}^{*} \cdot d Z^{*} \cdot d X_{r}^{*} \cdot d c^{*}
$$

with:

$$
\omega=\omega\left(p_{\tau}^{*}, T_{\tau}^{*}, Z^{*}, X_{r}^{*}, c^{*}\right)
$$

and:

$$
\mathcal{P}_{c o}=\mathcal{P}_{c o}\left(p_{\tau}^{*}, T_{\tau}^{*}, Z^{*}, X_{r}^{*}, c^{*}\right)
$$

where $\mathcal{P}_{c o}$ is the coupled PDF. Equation (66) is very difficult to solve because of the complex interactions between the different variables.

For that reason, in order to compute the mean reaction rate, several assumptions have to be made:

- $p_{\tau}$ and $X_{r}$ are constant in the domain,

- $T_{\tau}$ depends only on the fuel mass fraction, $Z$,

- $c$ is considered as homogeneous in the domain during combustion:

$$
c(Z)=\tilde{c} \quad \text { valid } \quad \forall Z
$$

This assumption, certainly the strongest one, probably has an impact on the combustion process. However, it is worth noting that it does not impact the computation of the start of combustion [13].

According to these assumptions, the coupled PDF reduces to a simple single-variable PDF:

$$
\mathcal{P}_{c o}=\mathcal{P}\left(Z^{*}\right)
$$

Now, the mean reaction-rate can be expressed as:

$$
\tilde{\omega}_{e s p}=\int \omega\left(p_{\tau}, T_{\tau}\left(Z^{*}\right), Z^{*}, X_{r}, \bar{c}\right) \cdot \mathcal{P}\left(Z^{*}\right) \cdot d Z^{*}
$$

The equation defining the local initial temperature of the mixture, $T_{\tau}$, as a function of the mixture fraction is:

$$
T_{\tau}=T_{\tau}(Z)=\tilde{T}_{\tau}+\left(\frac{T_{s}-\tilde{T}_{\tau}}{Z_{s}}\right) \cdot Z
$$

where $Z_{s}$ and $T_{s}$ are the values of the mixture fraction and the temperature at the liquid-gas interface under evaporating conditions respectively, and $\tilde{T}_{\tau}$ is the value of the mean tracer temperature, the definition of which is given below.
The mean progress variable is computed as:

$$
\tilde{c}=\frac{\int\left(Y\left(t, Z^{*}\right)-Y\left(t=0, Z^{*}\right)\right) \cdot \mathcal{P}\left(Z^{*}\right) \cdot d Z^{*}}{\int\left(Y\left(t_{e q}, Z^{*}\right)-Y\left(t=0, Z^{*}\right)\right) \cdot \mathcal{P}\left(Z^{*}\right) \cdot d Z^{*}}
$$

The equilibrium data are tabulated as a function of $p_{\tau}$, $T_{\tau}, \Phi$ and $X_{r}$, too. To complete the look-up table set of inputs, the specification of the values of $p_{\tau}$ and $T_{\tau}$ remains. These variables evolve in time because of the thermal losses and the cylinder volume variation. In order to compute $p_{\tau}$, an energy balance-equation, independent of combustion, has been set up:

$$
\begin{aligned}
\frac{d p_{\tau}}{d t}= & \frac{p_{\tau}}{m_{c y l} \cdot C_{v_{\tau}} \cdot \tilde{T}_{\tau}} \cdot\left[Q_{t h}-Q_{e v}+\sum h_{i / o} \cdot \frac{d m_{i / o}}{d t}+\right. \\
& \left.-\sum_{e s p_{\tau}} h_{e s p_{\tau}} \cdot \frac{d m_{e s p_{\tau}}}{d t}\right]+ \\
& p_{\tau} \cdot \frac{C_{p_{\tau}}}{C_{v_{\tau}}} \cdot\left[\sum_{e s p_{\tau}} \frac{1}{n_{e s p_{\tau}}} \cdot \frac{d n_{e s p_{\tau}}}{d t}-\frac{1}{V} \cdot \frac{d V}{d t}\right]
\end{aligned}
$$

where $m_{c y l}$ is the total mass contained in the cylinder, $C_{v}$ is the constant volume specific heat, $Q_{t h}$ represents the thermal loss flux, $Q_{e v}$ represents the thermal flux to evaporate the liquid fuel, $h$ is the enthalpy, $n$ is the mole number and $V$ is the cylinder volume. The subscript $\tau$ indicates the variables associated with the thermochemical conditions without combustion (tracer conditions), and the subscript $i / o$ refers to inlet/outlet variables. Enthalpies and specific heats depend on the thermodynamic state of the system:

$$
h_{e s p_{\tau}}=h_{e s p_{\tau}}\left(\tilde{T}_{\tau}\right) ; C_{p_{\tau}}=C_{p_{\tau}}\left(\tilde{T}_{\tau}\right) \text { and } C_{v_{\tau}}=C_{v_{\tau}}\left(\tilde{T}_{\tau}\right)
$$

Finally, $\tilde{T}_{\tau}$ is computed using the ideal-gas state equation:

$$
\tilde{T}_{\tau}=\frac{p_{\tau} \cdot M_{m i x_{\tau}}}{\rho_{m i x_{\tau}} \cdot \mathcal{R}}
$$

where $\rho_{m i x_{\tau}}$ and $\mathcal{R}$ are respectively the density of the mixture in tracer conditions and the universal gas constant. Thermal losses have been estimated by using the well established theory proposed in [67].

The reaction rates computed using the look-up table are exact only if the set of inputs refers to a table definition node. For all the other conditions, reaction rates are computed using extrapolation and linear interpolation techniques. It is worth investigating both these aspects. In the model, because of the highly non-linear behavior of the chemical kinetics, all kinds of extrapolation have been avoided; that is, in reading the look-up table, the species reaction rate is set to zero if initial conditions do not belong to the definition domain of the table. Concerning interpolation, equivalence ratio and molar fractions (table coordinates) do not linearly depend on fuel mass fraction (PDF coordinate); consequently an adapted interpolation method is necessary. 


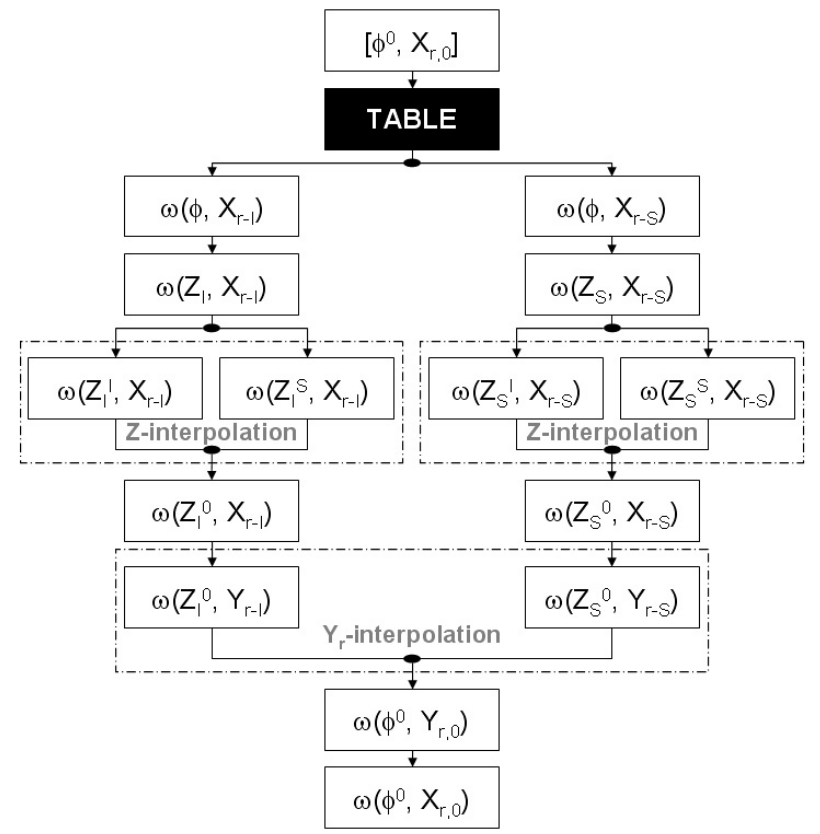

Figure 15

Interpolation method.

The method, presented in Figure 15, is detailed below. The subscripts/superscripts $S, I$ and 0 are relative to the higher and lower tabulated values (with respect to the reference value), and the reference value respectively. If subscripts, they are associated to the EGR rate, otherwise, if superscripts, they are associated to the equivalence ratio. The interpolation method, used to find the reaction rate associated to $\Phi^{0}$ and $X_{r_{0}}$, is resumed in the following steps:

- determining of the upper and lower tabulated values of $X_{r}$ with respect to $X_{r_{0}}$,

- once the value of the variable $X_{r}$ is fixed as $X_{r_{S / I}}$, using Equation (63), reaction rates $\omega\left(\Phi, X_{r_{S / I}}\right)$ can be expressed as $\omega\left(Z_{S / I}, X_{r_{S / I}}\right)$,

- determining the upper and lower values of $Z_{S / I}$ with respect to $Z_{S / I}^{0}$,

- linear interpolation in $Z_{S / I}$,

- to express the reaction rates $\omega\left(Z_{S / I}^{0}, X_{r_{S / I}}\right)$ as a function of $\omega\left(Z_{S / I}^{0}, Y_{r_{S / I}}\right)$, where $Y_{r}$ indicates the EGR mass fraction in the ambient gas,

- linear interpolation in $Y_{r}$,

- to express the resulting reaction rate $\omega\left(\Phi^{0}, Y_{r_{0}}\right)$ as a function of $\omega\left(\Phi^{0}, X_{r_{0}}\right)$.

\section{MODEL VALIDATION}

Validation of the global Diesel HCCI combustion model has been carried out by comparing the computed in-cylinder pressures with engine test-bench experimental data ${ }^{(3)}$. The engine used is the four cylinder turbo-charged G9T-NADI ${ }^{\mathrm{TM}}$ (Narrow Angle Direct Injection). More details concerning the engine can be found in [2].

The model has been validated on a set of eight steadystate operating points that are representative of the engine operating domain, Table 1 . The operating point No. 1 has been chosen as the reference operating point. In order to take into account the cylinder-to-cylinder variations, both the minimum and maximum mean cylinder pressures obtained from experimentation are plotted.

TABLE 1

Set of experimental engine operating points.

\begin{tabular}{c|c|c|c|c|c}
\hline $\begin{array}{c}\text { Point } \\
(-)\end{array}$ & $\begin{array}{c}\text { Crank speed } \\
(\mathrm{rpm})\end{array}$ & $\begin{array}{c}\text { IMEP } \\
(\mathrm{bar})\end{array}$ & $\begin{array}{c}\text { EGR rate } \\
(\%)\end{array}$ & $\begin{array}{c}\text { SOI } \\
\left({ }^{\circ}\right)\end{array}$ & $\begin{array}{c}\Phi \\
(-)\end{array}$ \\
\hline $\mathbf{1}$ & $\mathbf{1 4 9 7}$ & $\mathbf{6 . 0}$ & $\mathbf{9 . 3}$ & $\mathbf{6}$ & $\mathbf{0 . 4 8 9}$ \\
2 & 1497 & 6.1 & 19.8 & 6 & 0.613 \\
3 & 1497 & 6.1 & 36.3 & 6 & 0.885 \\
4 & 3491 & 6.1 & 0.2 & 15 & 0.356 \\
5 & 3494 & 10.1 & 0.3 & 18 & 0.465 \\
6 & 3491 & 20.2 & 0.3 & 27 & 0.674 \\
7 & 1497 & 6.3 & 36.8 & 10 & 0.888 \\
8 & 1497 & 6.2 & 36.7 & 8 & 0.886 \\
\hline
\end{tabular}

Two aspects concerning the simulations are noteworthy:

- the coefficients of the 0D model are tuned only so as to obtain best results at the reference operating point; they are not modified for the other points,

- the initial values of the simulations, such as pressure, temperature and gas mass-fractions, are obtained directly from the engine test-bench. Consequently, their values can not be adjusted to optimize the simulation results. This aspect is an additional challenge for the model.

The reference point has been studied in detail in order to have a deeper understanding of the combustion process.

\subsection{Analysis of the OD and the 3D Model Results}

In order to validate the different aspects correlated to the Diesel HCCI combustion model in an ICE application, such as liquid-fuel evaporation, spray formation, mixing process and chemical kinetics, the reference engine-operating-point, Table 1, was simulated using both the Diesel HCCI OD combustion model and the TKI-PDF 3D CFD model. The results were then compared, Figures 16-23.

(3) The presented experimental data represent the mean value of hundreds of acquired cycle pressure signals. 


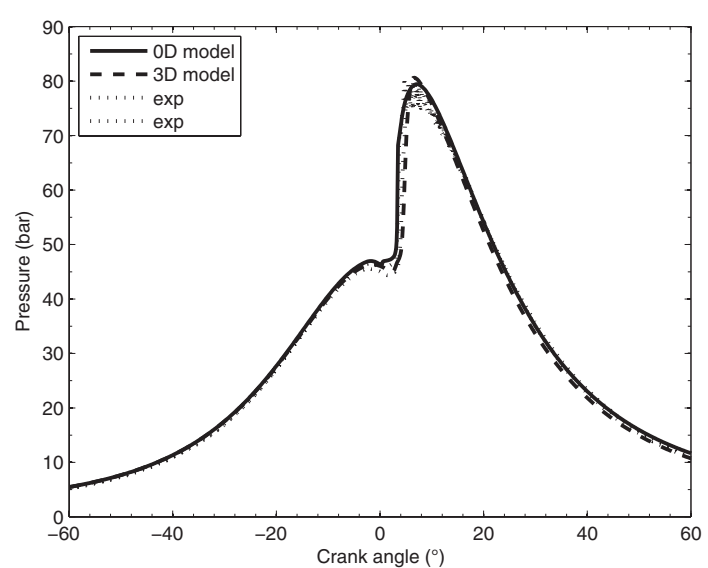

Figure 16

Pressure in the cylinder at the operating point No. 1. Comparison of $0 \mathrm{D}$ and $3 \mathrm{D}$ modelling results with experimental data.

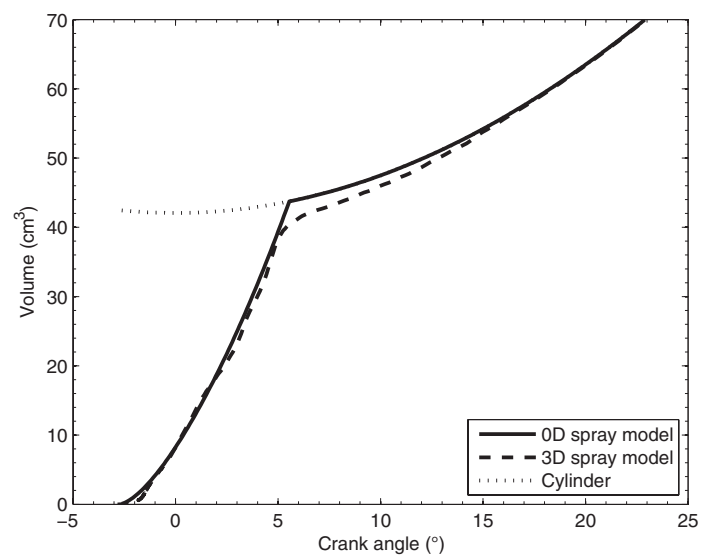

Figure 17

Spray volume at the operating point No. 1. Comparison of OD with $3 \mathrm{D}$ modelling results.

Figure 16 shows the evolution of the computed incylinder pressures plotted against the experimental pressurecurve envelope. As shown, the simulations are in good agreement with the experiments.

Figure 17 compares the evolution of the spray volumes ${ }^{(4)}$. As shown, near $5^{\circ}$ crankshaft angle, the spraygrowth rate, as obtained from the $3 \mathrm{D}$ model, decreases. This is for two major reasons, both depending on geometry:

- the first, due to the fact that the spray can hardly penetrate the interstitial volumes (e.g. the volume between the piston squish-area and the cylinder head, when the piston is close to the TDC (Top Dead Center),

(4) Concerning the 3D CFD model, spray volume has been defined as the total volume of the cells containing gaseous fuel.

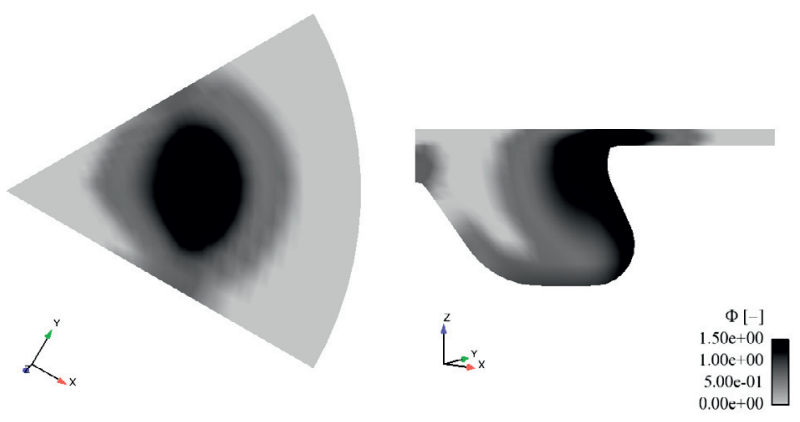

Figure 18

Equivalence ratio field in the cylinder at $5^{\circ}$ crankshaft angle. A cross view on a transverse plane close to the TDC (left), and a cross view on a longitudinal plane containg the injection axis (right).

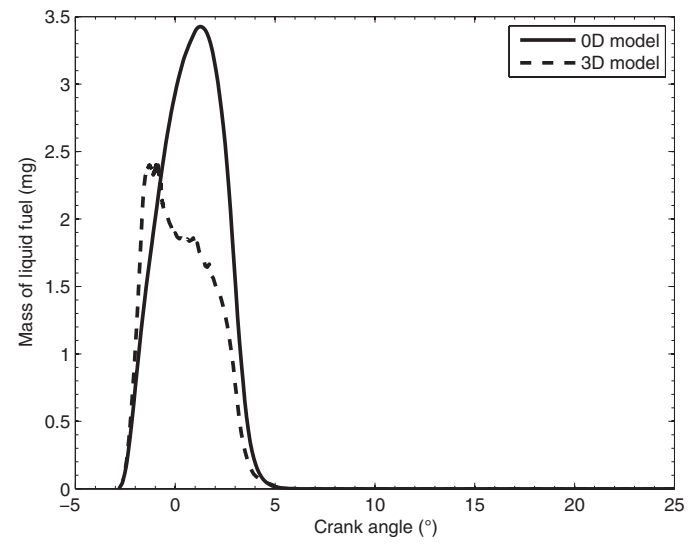

Figure 19

Liquid mass of fuel at the operating point No. 1. Comparison of $0 \mathrm{D}$ with $3 \mathrm{D}$ modelling results.

- the second, associated with the toroidal coherent turbulent-structure, which is generated by the impact of the spray on the piston bowl.

Figure 18 shows two views of the in-cylinder equivalence ratio field at $5^{\circ}$ crankshaft angle.

Figure 19 compares the two total liquid-fuel masses in the cylinder. As shown, the crankshaft-angle intervals necessary to complete liquid-fuel evaporation are very close for both models. The masses of liquid fuel in the cylinder are comparable even though the OD model underestimates the liquid-fuel evaporation rate.

Figure 20 compares the total masses of gases contained in the sprays. The two curves match each other well. The slight variation is mainly due to the geometrical reasons mentioned above.

Figure 21 compares the specific turbulent kineticenergies associated to the sprays computed by the OD and the 3D models. The comparison of the two curves shows 


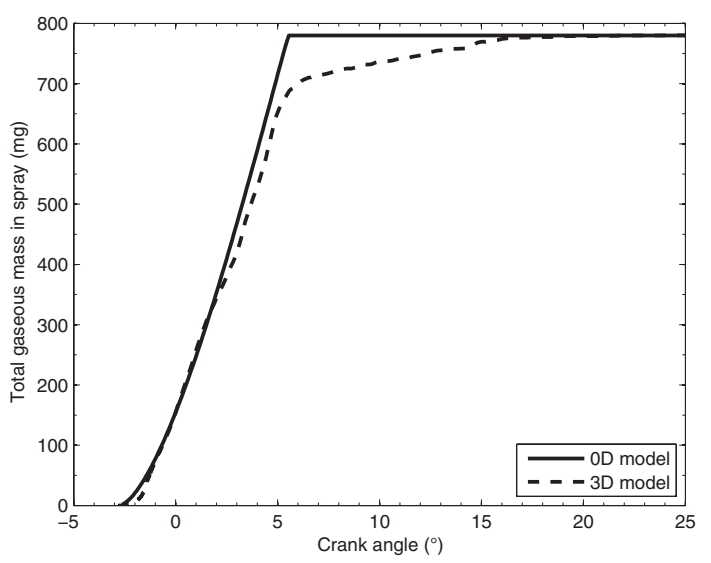

Figure 20

Spray mass at the operating point No. 1. Comparison of OD with $3 \mathrm{D}$ modelling results.

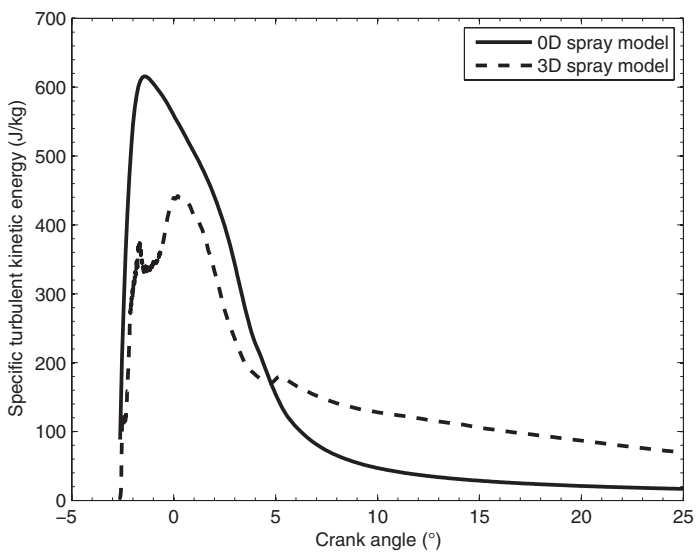

Figure 21

Spray specific turbulent kinetic-energy at the operating point No. 1. Comparison of $0 \mathrm{D}$ with 3D modelling results.

that the OD model well represents the first-order magnitude variations of the specific turbulent kinetic-energy.

Figure 22 shows the evolution of the fuel mixture-fraction PDF inside the sprays for different crankshaft-angle values. The crankshaft angle interval considered extends from the SOI (Start of injection) proximity to the EOC (End Of Combustion). As can be seen all along the interval, the 0D spray mixture model reproduces the air/fuel ratio stratification in the spray well.

Finally, Figure 23 compares the two heat release curves. The two heat-releases are in good agreement, and show that the 0D Diesel HCCI model is able to predict auto-ignition delays (see also Fig. 16) and the chemical reaction kinetics. The sharp shape of the curves shows that the heat release process is more representative of conventional Diesel combustion.
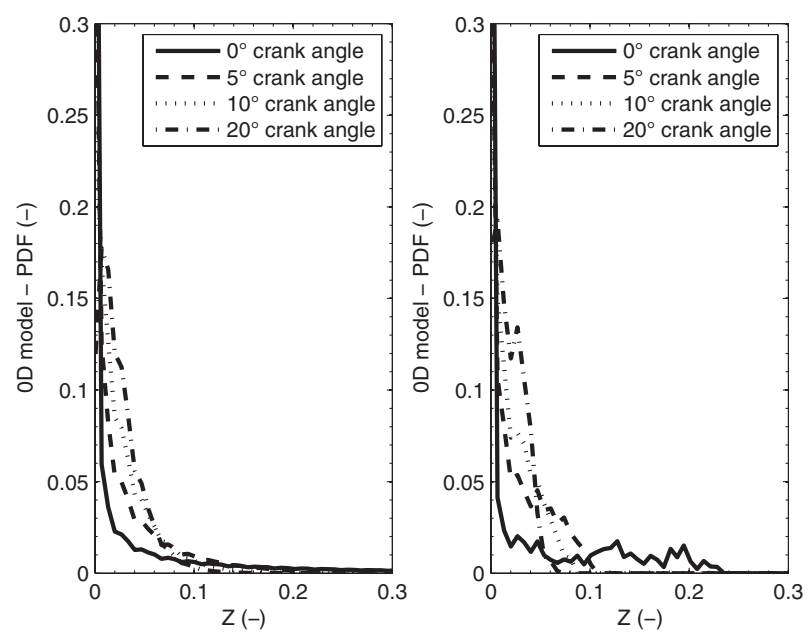

Figure 22

Evolution of the mixture fraction distribution at the operating point No. 1. Comparison of 0D (left) with 3D (right) modelling results at different crank angle values.

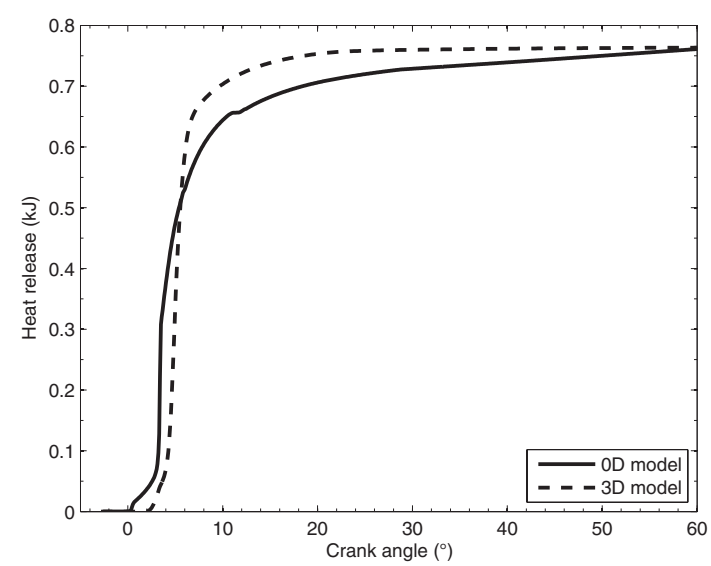

Figure 23

Heat release at the operating point No. 1. Comparison of $0 D$ with $3 \mathrm{D}$ modelling results.

\subsection{Comparison with Experimental Data}

The major challenge for the Diesel HCCI combustion model is to be able to adapt itself to all of the different engine operating-points. An engine operating point is completely defined once initial and boundary conditions are fixed. It follows without saying that model behavior must be sensitive to initial and boundary conditions.

Figures 24-26 show the in-cylinder pressures relative to eight different engine operating points. Computed results are plotted against experimental data.

Figure 24 shows the model's sensitivity to a variation of the IMEP value (points Nos. 4, 5 and 6). Computed pressure evolutions agree with the experimental curves. The most important aspects in combustion prediction, such as SOC 

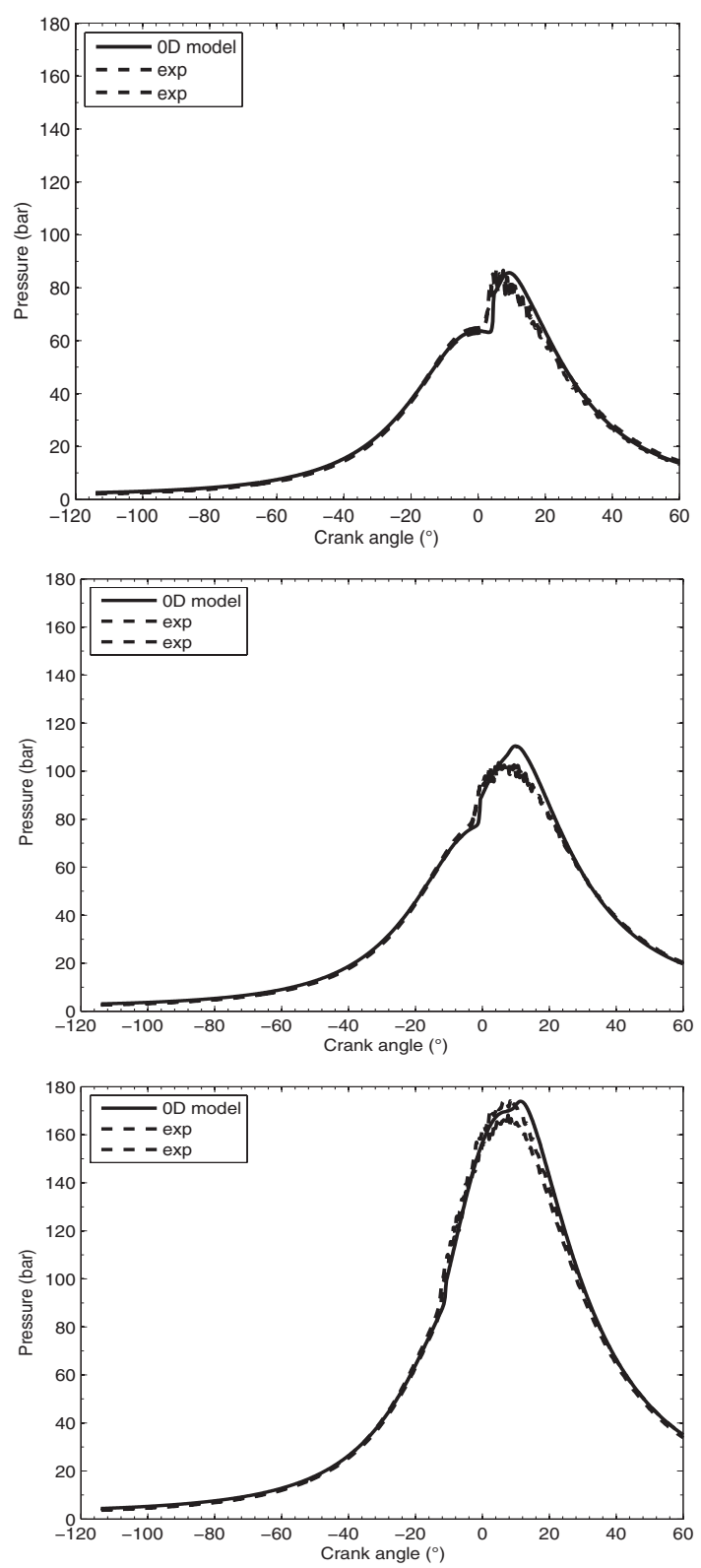

Figure 24

Sensitivity of the OD model to IMEP variations. Comparison of $0 \mathrm{D}$ modelling with experimental data. Curves of pressure refer to the operating points Nos. 4 (top), 5 (middle), 6 (bottom).

(Start Of Combustion), pressure peak value, and pressure peak position, are well reproduced. All three combustion processes are representative of conventional Diesel combustion.

Figure 25 shows the model's sensitivity to a variation of the SOI value while the other parameters stay constant (points Nos. 7, 8 and 3). The computed pressures follow the experimental results well. In particular, the main ignition-
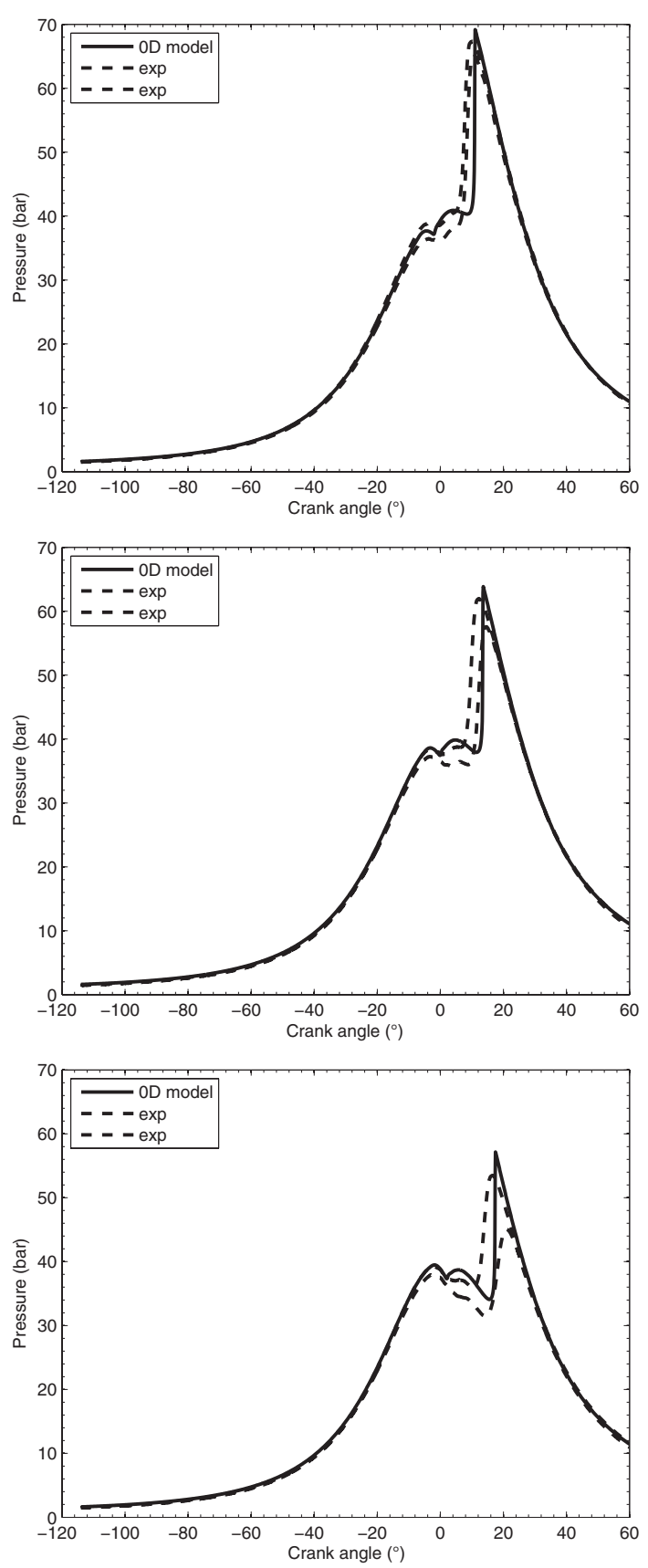

Figure 25

Sensitivity of the $0 \mathrm{D}$ model to SOI variations. Comparison of OD modelling with experimental data. Curves of pressure refer to the operating points Nos. 7 (top), 8 (middle), 3 (bottom).

delay growth and the reduction of the pressure peaks, with a reduction in the SOI, are well reproduced. All three operating points concern high EGR rates that, as already seen, favor cold-flame phenomena. Thus, the combustion processes are representative of HCCI combustion. This aspect is clearly put in evidence by the presence of two peaks in 

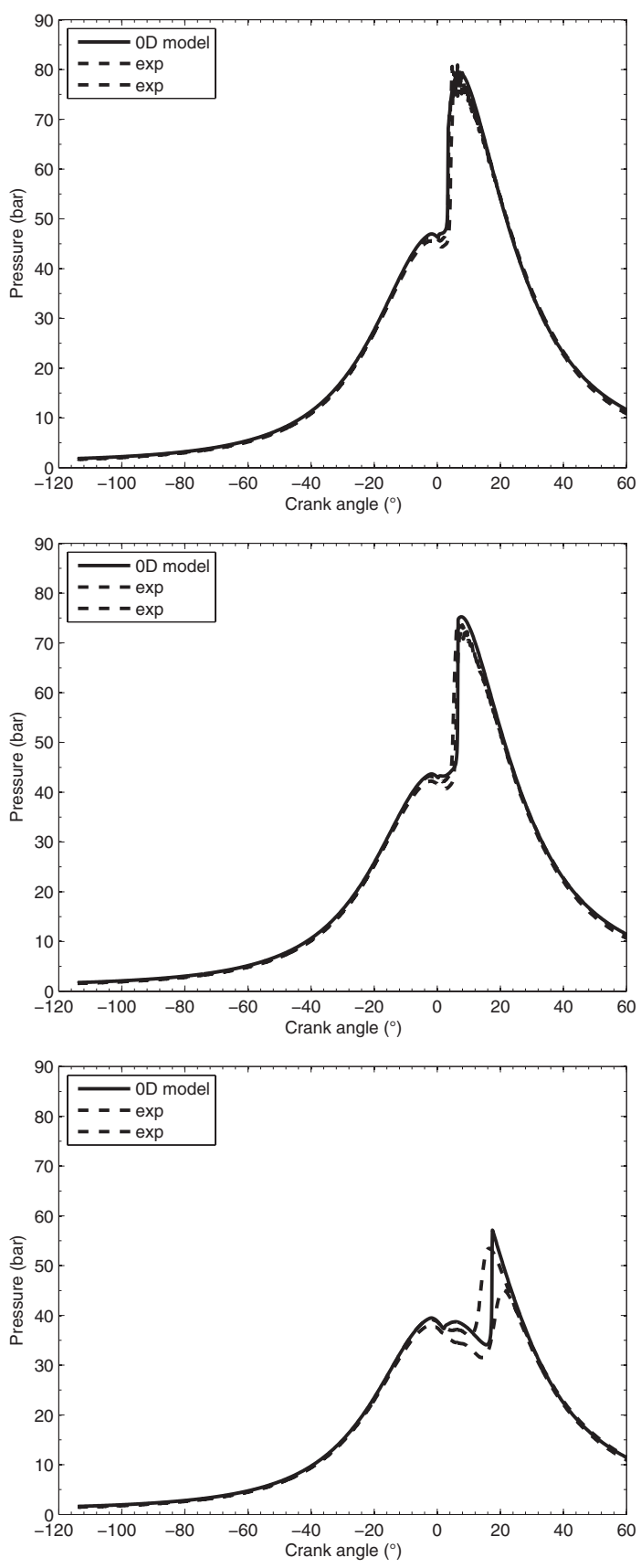

Figure 26

Sensitivity of the OD model to EGR rate variations. Comparison of 0D modelling with experimental data. Curves of pressure refer to the operating points Nos. 1 (top), 2 (middle), 3 (bottom).

the pressure curves: the first associated with the cold-flame heat-release, and the second associated with the main heatrelease.

Finally, Figure 26 shows the model's sensitivity to a variation of the EGR rate value (points No. 1, 2 and 3). This
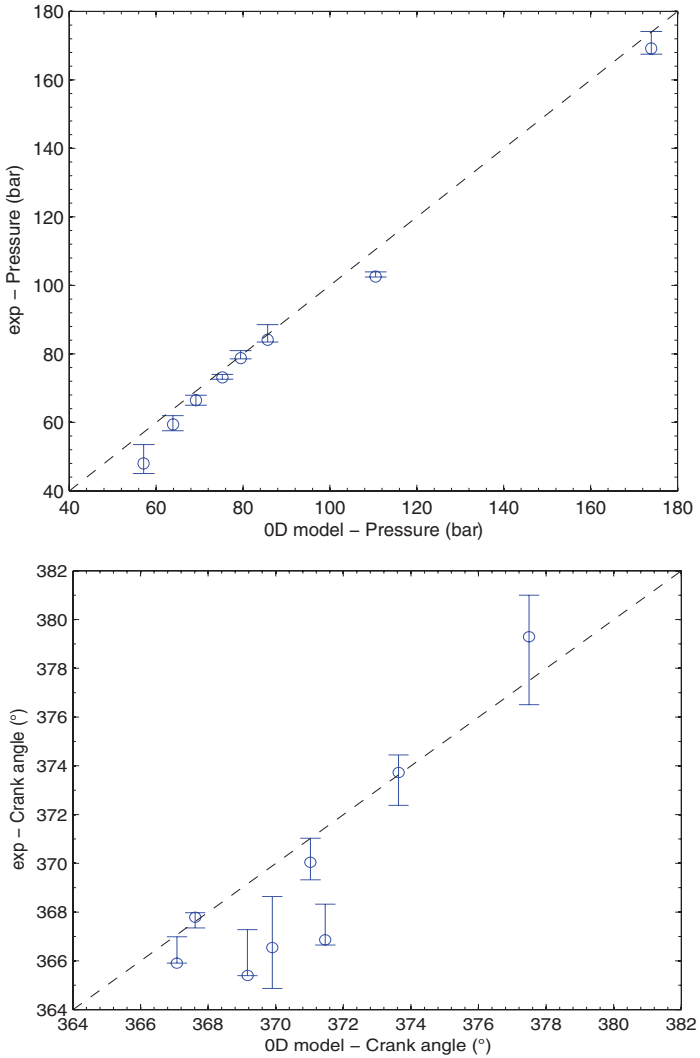

Figure 27

Correlation graphs relative to computed results and experimental data, for the engine operating points listed in Table 1 . The circles represent the values referred to the mean experimental curves, cylinder to cyinder variations are pointed out by using error bars. Curves refer to the maximum in-cylinder pressure values (top) and the corresponding crank angle values (bottom).

series of operating points considered highlights the potential of the model to predict the combustion process. In fact, with the growth of the EGR rate, the combustion process changes from conventional Diesel to HCCI.

In order to have a more detailed comparison of the $0 \mathrm{D}$ Diesel HCCI combustion-model results with experimental data, some characteristic variables of the combustion process are discussed in the following.

Figures 27-29 show some correlation graphs between computed results and experimental data ${ }^{(5)}$.

Figure 27 shows the correlation graphs relative to the maximum values of the in-cylinder pressure obtained for the different engine operating points and the corresponding crank angle values. As can be seen there is a good correlation between computations and experimental data.

(5) Information concerning the combustion progress are obtained by analyzing experimental in-cylinder pressure signals. 

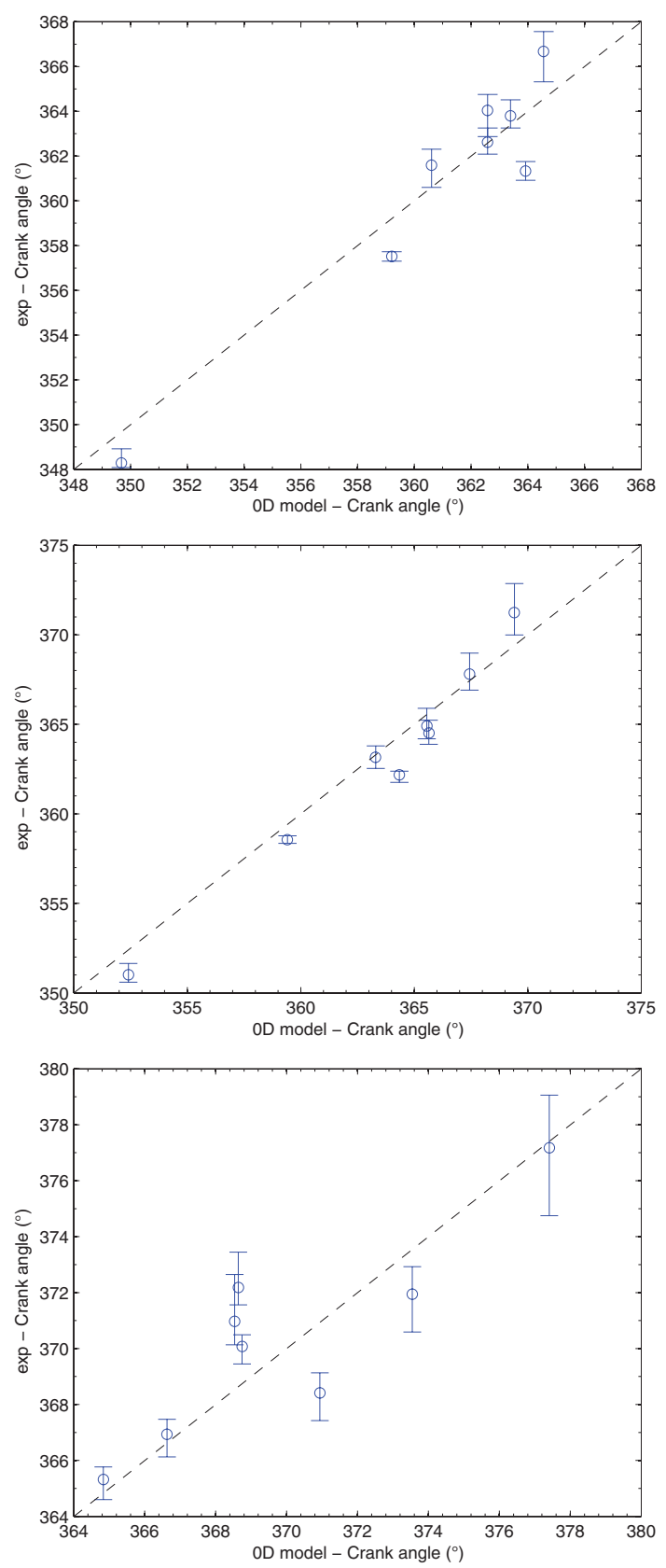

Figure 28

Correlation graphs relative to computed results and experimental data, for the engine operating points listed in Table 1. The circles represent the values referred to the mean experimental curves, cylinder to cyinder variations are pointed out by using error bars. Curves refer to the crank angle values at which the 5\% (top), $10 \%$ (middle) and 50\% (bottom) of the global injected energy is released.

Figure 28 shows the correlation graphs relative to the combustion progress for the different engine operating points. The crank angle values at which the $5 \%, 10 \%$ and

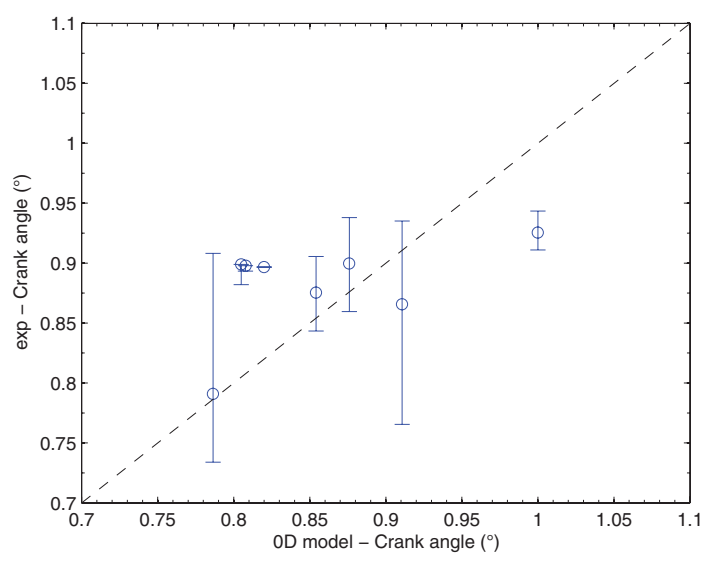

Figure 29

Correlation graphs relative to computed results and experimental data, for the engine operating points listed in Table 1. The circles represent the values referred to the mean experimental curves, cylinder to cyinder variations are pointed out by using error bars. Curve refer to the final values of the burned-mass fractions of injected-fuel.

$50 \%$ of the global injected-energy are released have been pointed out. Correlation graphs referred to crank angle values relative to the end of combustion (e.g. corresponding to the $90 \%$ of the global injected-energy) are here omitted as these values, in reason of the very particular adopted engine-control strategies, are not often reached, Figure 29. As shown, the model well predict the mixture auto-ignition angular position (top), which is the most important variable to catch in conventional Diesel and HCCI combustion modelling. The evolution of the combustion process (middle and bottom) is quite well predicted by the model, at least up to the release of half of the injected energy.

Figure 29 refers to the final values of the burned-mass fractions of injected-fuel. As can be seen, the combustion processes are often incomplete and the experimental data present wide intervals of variation. These two aspects, if occurring at the same time, are symptomatic of unstable combustion processes. For that reason computed results are considered as satisfactory.

\section{CONCLUSION}

This paper presents an original approach to Diesel HCCI combustion modelling. The main contribution of the model concerns the detailed description of the spray using a OD formalism. In order to carry this out, tools hitherto commonly adopted in 3D CFD models (such as PDF and $\kappa-\epsilon$ turbulence model) have been modified and integrated in an innovative 0D model. As a consequence, it is possible to have access to a statistical local description of the 
air/fuel mixture. It consists of an estimate of the local temperature and local composition values. The spray model has then been coupled to a complex-chemistry tabulation method that computes reaction rates associated with the local thermochemical-conditions. The spray model has been widely discussed and validated with results obtained with the TKI-PDF 3D CFD model developed at the IFP. Finally the global Diesel HCCI combustion model has been validated with experimental data on a wide range of engine operating conditions.

This approach is seen to be very promising, mainly for the following reasons:

- it is essentially based on physical considerations (this allows a direct comparison of the computed results with experimental data),

- it gives a detailed description of the dynamics of spray formation and the combustion process, and can therefore be a useful tool in engine control strategy development,

- the detailed chemistry tabulation method gives potential access to all species playing a role in the combustion process; this aspect is very interesting in expanding the study to include pollutant formation mechanisms,

- the model is able to predict both conventional Diesel and HCCI combustion,

- the model is sensitive to both boundary and initial conditions,

- the CPU time required to perform a complete enginecycle simulation is of the order of $10^{2}$ of real time.

Below are some short-term actions envisaged to further improve the existing model:

- extending the spray model to the multi-injection strategy management,

- investigating the impact on the oxidation process of a combustion progress-variable variance in the reactive mixture,

- defining a new complex-chemistry tabulation more orientated towards prediction of pollutant emissions. Main changes shall concern the surrogate fuel choice and the tabulation method. In particular, a species mass-fraction tabulation approach, instead of a species reaction-rate one, seems to be more promising in ICE modelling.

Further investigations of these topics will be undertaken by the authors in their future works.

\section{REFERENCES}

1 Lafossas F.A., Marbaix M., Menegazzi P. (2007) Development and application of a 0D D.I. Diesel combustion model for emissions prediction, SAE Technical Paper No. 2007-01-1841.

2 Albrecht A., Corde G., Knop V., Boie H., Castagne M. (2005) 1D simulation of turbocharged gasoline direct injection engine for transient strategy optimization, SAE Technical Paper No. 2005-01-0693.
3 Albrecht A., Chauvin J., Lafossas F.A., Potteau S., Corde G. (2006) Development of highly premixed combustion Diesel engine model: from simulation to control design. SAE Technical Paper No. 2006-01-1072.

4 Tao F., Liu Y., Rempelewert H., Foster D.E., Reitz R.D. (2005) Modeling the effects of EGR and injection pressure on the soot formation in a High-Speed Direct-Injection (HSDI) Diesel engine using a multi-step phenomenological soot model, $S A E$ Technical Paper No. 2005-01-0121.

5 Vibe I.I. (1970) Brennverlauf und Kreisprozess von Verbrennungsmotoren, VEB Verlag Technik.

6 Heywood J.B. (1988) Combustion in Compression-Ignition engines, in Internal combustion engine fundamentals, McGraw-Hill, New York.

7 Cesario N., Muscio C., Farina M., Amato P., Lavorgna M. (2004) Modelling the rate of heat release in common rail Diesel engines: a soft computing approach, SAE Technical Paper No. 2004-01-2967.

8 Arsie I., Di Genova F., Pianese C., Rizzo G., Sorrentino M., Caraceni A., Cioffi P., Flauti G. (2003) A single-zone model for combustion and NOx simulation in common-rail multi-jet Diesel engines, SAE Technical Paper No. 2003-01-79.

9 Hiroyasu H., Kadota T., Arai M. (1983) Development and use of a spray combustion modeling to predict Diesel engine efficiency and pollutant emissions, Bull. JSME 26, 214, 569-583.

10 Asay R.J., Svensson K.I., Tree D.R. (2004) An empirical, mixing-limited, zero-dimensional model for Diesel combustion, SAE Technical Paper No. 2004-01-0924.

11 Dec J.E. (1997) A conceptual model of DI Diesel combustion based on laser-sheet imaging, SAE Technical Paper No. 970873.

12 Mauviot G., Albrecht A., Poinsot T. (2006) A new 0D approach for Diesel combustion modeling coupling probability density function with complex chemistry, SAE Technical Paper No. 2006-01-3332.

13 Mauviot G. (2007) Développement d'une modélisation phénoménologique de chambres de combustion de moteurs à piston par réduction de modèle physique 3-D dans la perspective d'une intégration dans un outil de simulation système, $P h D$ Thesis, UPMC.

14 Barba C., Burkhardt C., Boulouchos K., Bargende M. (1999) An empirical model for precalculating the combustion rate of the Common Rail Diesel engine for passenger cars, Motortechnische Z. 60, 4, 262-270.

15 Barba C., Burkhardt C., Boulouchos K., Bargende M. (2000) A phenomenological combustion model for heat release rate prediction in high speed DI Diesel engines with common-rail injection, SAE Technical Paper No. 2000-01-2933.

16 Chmela F., Orthaber G. (1999) Rate of heat release prediction for direct injection Diesel engines based on purely mixing controlled combustion, SAE Technical Paper No. 1999-01-0186.

17 Chmela F., Engelmayer M., Pirker G., Wimmer A. (2004) Prediction of turbulence controlled combustion in Diesel engines, THIESEL conference on thermo and fluid dynamic processes in Diesel engines, Valence - Spain, 2004. 
18 Schihl P., Tasdemir J., Schwarz E., Bryzik W. (2002) Development of a zero-dimensional heat release model for application to small bore Diesel engines, SAE Technical Paper No. 200201-0073.

19 Kouremenos D.A., Rakopoulos C.D., Hountalas D.T. (1997) Multi-zone combustion modelling for the prediction of pollutants emissions and performance of DI Diesel engines, SAE Technical Paper No. 970635.

20 Jaine T. (2004) Simulation zérodimensionnelle de la combustion dans un moteur Diesel à Injection Directe, PhD Thesis, Université d'Orléans.

21 Kong S.C., Ayoub N., Reitz D. (1992) Modeling combustion in compression ignition homogeneous charge engine. SAE Technical Paper No. 920512.

22 Kong S.C., Marriot C.D., Reitz C.D., Christensen M. (2001) Modeling and experiments of HCCI engine combustion using detailed chemical kinetics with multidimensional CFD, SAE Technical Paper No. 2001-01-1026.

23 Kong S.C., Han Z., Reitz D. (2002) The development and application of a diesel ignition and combustion model for multidimensional engine simulation, SAE Technical Paper No. 950278 .

24 Kong S.C., Marriot C.D., Rutland C.J., Reitz D. (2002) Experiments and CFD modeling of direct injection gasoline HCCI engine combustion, SAE Technical Paper No. 2002-01-1925.

25 Patel A., Kong S.C., Reitz R.D. (2004) Development and validation of a reduced reaction mechanism for HCCI engine simulation, SAE Technical Paper No. 2004-01-0558.

26 Nishida K., Hiroyasu H. (1989) Simplified three-dimensional modeling of mixture formation and combustion in a Diesel engine, SAE Technical Paper No. 890269.

27 Hasse C., Barths H., Peters N. (1999) Modeling the effects of split-injections in Diesel engines using representative interactive flamelets, SAE Technical Paper No. 1999-01-3574.

28 Hasse C., Bikas G., Peters N. (2000) Modeling diesel combustion using the eulerian particle flamelet model (epfm), SAE Technical Paper No. 2000-01-2934.

29 Barths H., Pitsch H., Peters N. (1999) 3D simulation of DI diesel combustion and pollutant formation using a twocomponent reference fuel, Oil Gas Sci. Technol. 54, 2, 233244.

30 Michel J.B., Colin O., Veynante D. (2008) Modeling ignition and chemical structure of partially premixed turbulent flames using tabulated chemistry, Combust. Flame 152, 1-2, 80-99.

31 Peters N., Rogg B. (1993) Reduced kinetic mechanisms for applications in combustion systems, Springer Verlag, Heidelberg.

32 Peters N. (2000) Nonpremixed turbulent combustion, in Turbulent combustion, Cambridge University Press, Cambridge.

33 Colin O., Benkenida A., Angelberger C. (2003) 3D Modeling of Mixing, ignition and combustion phenomena in highly stratified gasoline engine, Oil Gas Sci. Technol. 58, 1, 47-52.

34 Colin O., Benkenida A. (2004) The 3-zones extended coherent flame model (ECFM3Z) for computing premixed/diffusion combustion, Oil Gas Sci. Technol. 59, 6, 593-609.
35 Wang Z., Wang J., Shuai S. (2004) Numerical simulation of HCCI engine with multistage gasoline Direct Injection using 3d-cfd with detailed chemistry, SAE Technical Paper No. 200401-0563.

36 Wang Z., Shuai S., Wang J., Tian G., An X. (2006) Modeling of HCCI combustion from OD to 3D, SAE Technical Paper No. 2006-01-1364.

37 Knop V., Jay S. (2006) Latest developments in gasoline AutoIgnition modelling applied to an optical CAI ${ }^{\mathrm{TM}}$ engine, Oil Gas Sci. Technol. 61, 1, 121-137.

38 Pires-da-Cruz A., Baritaud T., Poinsot T.J. (2001) Self-ignition and combustion modeling of initially nonpremixed turbulent systems, Combust. Flame 124, 1-2, 65-81.

39 Bruneaux G. (2001) Liquid and vapor spray structure in high pressure Common Rail Diesel injector, Atomization Spray. 11, $5,533-556$.

40 Bruneaux G., Augé M., Lemenand C. (2004) A study of Combustion structure in high pressure single hole Common Rail Direct Diesel Injection using laser induced fluorescence of radicals, COMODIA Congress, Yokohama - Japan, 2004.

41 Bruneaux G. (2005) Mixing process in high pressure Diesel jets by normalized laser induced exciplex fluorescence. Part I: free jet, SAE Technical Paper No. 2005-01-2100.

42 Verhoeven D., Vanhemelryck J.-L., Baritaud T. (1998) Macroscopic and ignition characteristics of high-pressure sprays of single-component fuels, SAE Technical Paper No. 981069.

43 Hiroyasu H., Arai M. (1990) Structures of fuel sprays in Diesel engines, SAE Technical Paper No. 900475.

44 Jaine T., Benkenida A., Menegazzi P., Higelin P. (2003) Zero dimensional computation of Diesel spray - comparison with experiments and 3D model, 6th International Conference on Engines for Automobile, Capri - Italy, 2003.

45 Subramanian G. (2005) Modélisation de l'auto-inflammation : analyse des effets de la dilution par les gaz brûlés et des interactions avec la turbulence dédiée aux moteurs Diesel à charge homogène, PhD Thesis, INSA Rouen.

46 Pope S.B. (1985) PDF methods for turbulent reactive flows, Prog. Energ. Combust. 19, 11, 119-192.

47 Gicquel O., Darabiha N., Thévenin D. (2000) Laminar premixed hydrogen/air counterflow flame simulations using flame prolongation of ILDM with differential diffusion, Proc. Combust. Inst. 28, 1901-1908.

48 Veynante D., Vervisch L. (2002) Turbulent combustion modeling, Prog. Energ. Combust. 28, 3, 193-266.

49 Lefebvre A.H. (1989) Drop evaporation, in Atomization and sprays, Hemisphere Publishing Corporation, United States of America.

50 Reid R.C., Prausnitz J.M., Poling B.E. (1987) The properties of gases $\mathcal{E}$ liquids, McGraw-Hill, United States of America.

51 Ghassemi H., Baek S.W., Khan S.Q. (2006) Experimental study on binary droplet evaporation at elevated pressures and temperatures, Combust. Sci. Technol. 178, 6, 1031-1053.

52 Siebers D.L. (1998) Liquid-phase fuel penetration in Diesel sprays, SAE Technical Paper No. 980809. 
53 Siebers D. (1999) Scaling liquid-phase fuel penetration in diesel sprays based on mixing-limited vaporization, SAE Technical Paper No. 1999-01-0528.

54 Naber J.D., Siebers D. (1996) Effects of gas density and vaporization on penetration and dispersion of diesel sprays, $S A E$ Technical Paper No. 960034.

55 Desantes J.M., Payri R., Salvador F.J., Gil A. (2005) Development and validation of a theoretical model for diesel spray penetration, Fuel 85, 7-8, 910-917.

56 Girimaji S.S. (1991) Assumed $\beta$-PDF Model for Turbulent Mixing: Validation and Extension to Multiple Scalar Mixing, Combust. Sci. Technol. 78, 177-196.

57 Kuo K.K. (2005) Gaseous diffusion flames and combustion of a single liquid fuel droplet, in Principles of combustion, Wiley J. (ed.), John Wiley \& Sons, Hoboken - New Jersey.

58 Givler S.D., Abraham J. (1996) Supercritical droplet vaporization and combustion studies, Prog. Energ. Combust. 22, 4 , $1-28$.

59 Sirignano W.A. (2004) Droplet behavior at near-critical, transcritical, and supercritical conditions, in Fluid dynamics and transport of droplets and sprays, Cambridge University Press, Irvine.

60 Neely G.D., Sasaky S., Huang Y., Leet J.A., Stewart D.W. (2005) New Diesel emission control strategies to meet US Tier
2 emissions regulations, SAE Technical Paper No. 2005-011091

61 Kee R.J., Rupley F.M., Miller J.A. (1989) CHEMKIN-II: a fortran chemical kinetics package for the analysis of gasphase chemical kinetics, Sandia National Laboratories report No. SNL-89-8009.

62 Curran H.J., Gaffuri P., Pitz W.J., Westbrook C.K. (1998) A comprehensive modeling study of $\mathrm{n}$-heptane oxidation, Combust. Flame 114, 1-2, 149-177.

63 Maas U., Pope S.B. (1992) Implementation of simplified chemical kinetics based on low-dimensional manifolds, Proc. Combust. Inst. 24, 1, 103-112.

64 Maas U., Pope S.B. (1992) Simplifying chemical kinetics: intrinsic low-dimensional manifolds in composition space, Combust. Flame 88, 3-4, 239-264.

65 Embouazza M. (2005) Étude de l'auto-allumage par réduction des schémas cinétiques chimiques. Application à la combustion homogène Diesel, PhD Thesis, École Centrale de Paris.

66 Gauthier B.M., Davidson D.F., Hanson R.K. (2004) Shock tube determination of ignition delay times in full-blend and surrogate fuel mixtures, Combust. Flame 139, 4, 300-311.

67 Sihling K., Woschni G. (1979) Experimental investigation of the instantaneous heat transfer in the cylinder of a high speed Diesel engine, SAE Technical Paper No. 790833. 


\section{APPENDIX: $\beta-P D F$ VARIANCE FORMULA PROOF}

Mathematical proof of Equation (54) holds as follows. The fuel mass-fraction distribution variance is defined as:

$$
\widetilde{Z^{\prime \prime 2}}=\frac{1}{m_{S}} \cdot \int_{m_{S}} Z^{\prime 2} \cdot d m=\frac{1}{m_{S}} \cdot \int_{m_{S}}\left(\left.Z\right|_{d m}-\tilde{Z}\right)^{2} \cdot d m
$$

hence, expliciting the PDF of the fuel mass-fraction:

$$
\widetilde{Z^{\prime \prime 2}}=\int_{0}^{Z_{s}}\left(Z^{*}-\tilde{Z}\right)^{2} \cdot \mathcal{P}\left(Z^{*}\right) \cdot d Z^{*}
$$

Differentiating Equation (78):

$$
\begin{aligned}
\frac{d \widetilde{Z^{\prime \prime 2}}}{d t}= & \underbrace{\int_{0}^{Z_{s}} \frac{d\left(Z^{*}-\tilde{Z}\right)^{2}}{d t} \cdot \mathcal{P}\left(Z^{*}\right) \cdot d Z^{*}}_{(a)}+ \\
& +\underbrace{\int_{0}^{Z_{s}}\left(Z^{*}-\tilde{Z}\right)^{2} \cdot \frac{d \mathcal{P}\left(Z^{*}\right)}{d t} \cdot d Z^{*}}_{(b)}
\end{aligned}
$$

Developping the term $(a)$ of Equation (79):

$$
\begin{gathered}
\int_{0}^{Z_{s}} \frac{d\left(Z^{*}-\tilde{Z}\right)^{2}}{d t} \cdot \mathcal{P}\left(Z^{*}\right) \cdot d Z^{*}= \\
\int_{0}^{Z_{s}}\left(\frac{d \tilde{Z}^{2}}{d t}-2 \cdot Z^{*} \cdot \frac{d \tilde{Z}}{d t}\right) \cdot \mathcal{P}\left(Z^{*}\right) \cdot d Z^{*}= \\
\frac{d \tilde{Z}^{2}}{d t} \cdot \int_{0}^{Z_{s}} \mathcal{P}\left(Z^{*}\right) \cdot d Z^{*}-2 \cdot \frac{d \tilde{Z}}{d t} \cdot \int_{0}^{Z_{s}} Z^{*} \cdot \mathcal{P}\left(Z^{*}\right) \cdot d Z^{*}= \\
\frac{d \tilde{Z}^{2}}{d t}-2 \cdot \tilde{Z} \cdot \frac{d \tilde{Z}}{d t}=\frac{d \tilde{Z}^{2}}{d t}-\frac{d \tilde{Z}^{2}}{d t}=0
\end{gathered}
$$

As shown, the term (a) does not contribute to the variance variation.

Concerning the term (b) of Equation (79), it represents the variation of the PDF shape in time. In order to correctly describe the PDF evolution, the different contributions to the variance variation will be determined. More precisely, the impacts of the mixture-zone inputs, namely the entrained ambient-gas and the evaporated fuel, and of turbulence will be presented in detail. Henceforth, global PDF will be subdivided into three contributions:

$-\mathcal{P}_{A}$, the probability to have a local mixture-fraction in the spray at $Z=Z_{A}=0$; that is, the composition of pure ambient-gas (a perfectly stirred mixture of air and eventually EGR) entrained in the spray,

- $\mathcal{P}_{s}$, the probability to have a local mixture-fraction in the spray at $Z=Z_{s}$; that is, the mixture composition at liquidgas interface during evaporation process,

- $\mathcal{P}_{c}$, the probability to have a local mixture-fraction in the spray different from $Z_{A}$ and $Z_{S}$. Henceforth, it will be called the complementary mixture-fraction probability.
$\mathcal{P}_{A}$ and $\mathcal{P}_{s}$ at each instant of time have a well-known composition. Consequently, in the composition space, they can be represented using a Dirac function, $\psi$.

On the other hand, turbulence acts on the overall mixturefraction distribution and contributes to dissipate the distribution variance. Physically, its action represents the mixture homogenization caused by turbulent-mixing process.

In the following, the different term contributions to the variance variation will be detailed.

\section{Entrained-mass Contribution}

At a given time, $t_{0}$, the probability to have in the spray a local mixture-composition at $Z=Z_{A}$ is:

$$
\mathcal{P}\left(Z_{A}, t_{0}\right)=\mathcal{P}_{A_{0}}
$$

after a short interval of time, $\delta t$, the spray entrains a certain amount of mass, $\delta m_{A}$. Hence:

$$
\mathcal{P}\left(Z_{A}, t_{0}+\delta t\right)=\mathcal{P}_{A_{0}} \cdot \frac{m_{S}}{m_{S}+\delta m_{A}}+\frac{\delta m_{A}}{m_{S}+\delta m_{A}}
$$

Computing the derivative of $\mathcal{P}\left(Z_{A}\right)$ as the limit of the incremental ratio gives:

$$
\frac{d \mathcal{P}\left(Z_{A}\right)}{d t}=\lim _{\delta t \rightarrow 0} \frac{\mathcal{P}\left(Z_{A}, t_{0}+\delta t\right)-\mathcal{P}\left(Z_{A}, t_{0}\right)}{\delta t}=\frac{1}{m_{S}} \cdot \frac{d m_{A}}{d t}
$$

Hence, its contribution to the variance is:

$$
\begin{gathered}
\int_{0}^{Z_{S}}\left(Z^{*}-\tilde{Z}\right)^{2} \cdot\left(\frac{1}{m_{S}} \cdot \frac{d m_{A}}{d t}\right) \cdot \psi\left(Z^{*}-Z_{A}\right) \cdot d Z^{*}= \\
\left(Z_{A}-\tilde{Z}\right)^{2} \cdot \frac{1}{m_{S}} \cdot \frac{d m_{A}}{d t}=\frac{\tilde{Z}^{2}}{m_{S}} \cdot \frac{d m_{A}}{d t}
\end{gathered}
$$

\section{Evaporation-process Contribution}

Adopting the same way of proceeding, the evaporationprocess impact on the PDF holds:

$$
\frac{d \mathcal{P}\left(Z_{s}\right)}{d t}=\lim _{\delta t \rightarrow 0} \frac{\mathcal{P}\left(Z_{s}, t_{0}+\delta t\right)-\mathcal{P}\left(Z_{s}, t_{0}\right)}{\delta t}=\frac{1}{m_{S}} \cdot \frac{d m_{s}}{d t}
$$

hence, its contribution to variance is:

$$
\begin{gathered}
\int_{0}^{Z_{s}}\left(Z^{*}-\tilde{Z}\right)^{2} \cdot\left(\frac{1}{m_{S}} \cdot \frac{d m_{s}}{d t}\right) \cdot \psi\left(Z^{*}-Z_{s}\right) \cdot d Z^{*}= \\
\frac{1}{m_{S}} \cdot\left(Z_{s}-\tilde{Z}\right)^{2} \cdot \frac{d m_{s}}{d t}
\end{gathered}
$$

Fuel evaporation process at liquid-gas interface at saturated conditions implies to introduce in the spray an homogeneous mixture of pure ambient-air and pure fuel in proportions established by the value of $Z_{s}$. As the necessary ambientair mass is already contained in the spray, its transfer from one value of mixture fraction to another represents a further contribution to the variance variation. In the presented 
approach, it has been done the hypothesis that liquid fuel evaporates in pure ambient-air. Locally, by definition:

$$
Z=\frac{m_{F}}{m_{F}+m_{A}}
$$

where $m_{A}$ is the mass of pure ambient-air in the spray. Hence, for a given fuel evaporation-rate (evaporating at saturated conditions), $d m_{F} / d t$, the total mass at saturated composition introduced in the spray is:

$$
\frac{d m_{s}}{d t}=\frac{\left(d m_{F}+d m_{A}\right)_{s}}{d t}=\frac{1}{Z_{s}} \cdot \frac{d m_{F}}{d t}
$$

Consequently, the corresponding withdrawn ambient-air mass, $d m_{A_{w}}$, is:

$$
\frac{d m_{A_{w}}}{d t}=\left(1-\frac{1}{Z_{S}}\right) \cdot \frac{d m_{F}}{d t}
$$

It follows that the impact on the PDF is:

$$
\frac{d \mathcal{P}\left(Z_{A}\right)}{d t}=\lim _{\delta t \rightarrow 0} \frac{\mathcal{P}\left(Z_{A}, t_{0}+\delta t\right)-\mathcal{P}\left(Z_{A}, t_{0}\right)}{\delta t}=\frac{1}{m_{S}} \cdot \frac{d m_{A_{w}}}{d t}
$$

and the impact on the variance variation is:

$$
\begin{gathered}
\int_{0}^{Z_{S}}\left(Z^{*}-\tilde{Z}\right)^{2} \cdot\left(\frac{1}{m_{S}} \cdot \frac{d m_{A_{w}}}{d t}\right) \cdot \psi\left(Z^{*}-Z_{A}\right) \cdot d Z^{*}= \\
\left(Z_{A}-\tilde{Z}\right)^{2} \cdot \frac{1}{m_{S}} \cdot \frac{d m_{A_{w}}}{d t}=\tilde{Z}^{2} \cdot \frac{1}{m_{S}} \cdot \frac{d m_{A_{w}}}{d t}
\end{gathered}
$$

as $Z_{A}=0$.

\section{Complementary Mixture-fraction Contribution}

The used $\beta$-PDF is a normalized statistical-tool. Consequently, the following relation must always be verified:

$$
\int_{0}^{Z_{s}} \mathcal{P}\left(Z^{*}\right) \cdot d Z^{*}=1
$$

Taking advantage of Equation (92), at every time, $t$, it is possible to know the probability to have in the spray a local composition $Z=Z_{c}$ :

$$
\mathcal{P}\left(Z_{c}\right)=\int_{0}^{Z_{s}} \mathcal{P}\left(Z^{*}\right) \cdot d Z^{*}-\mathcal{P}\left(Z_{A}\right)-\mathcal{P}\left(Z_{S}\right)
$$

Differentiating Equation (93):

$$
\frac{d \mathcal{P}\left(Z_{c}\right)}{d t}=-\frac{d \mathcal{P}\left(Z_{A}\right)}{d t}-\frac{d \mathcal{P}\left(Z_{s}\right)}{d t}
$$

being the first right-hand term of Equation (93) identically equal to unity.

The contribution of the complementary mixture-fraction to the variance variation is then computed as:

$$
\begin{gathered}
\int_{0}^{Z_{s}}\left(Z^{*}-\tilde{Z}\right)^{2} \cdot \frac{d \mathcal{P}\left(Z_{c}\right)}{d t} \cdot d Z^{*}= \\
-\int_{0}^{Z_{s}}\left(Z^{*}-\tilde{Z}\right)^{2} \cdot \frac{1}{m_{S}} \cdot\left(\frac{d m_{A}}{d t}+\frac{d m_{s}}{d t}+\frac{d m_{A_{w}}}{d t}\right) \cdot d Z^{*}= \\
-\frac{\widetilde{Z^{\prime 2}}}{m_{S}} \cdot\left(\frac{d m_{A}}{d t}+\frac{d m_{s}}{d t}+\frac{d m_{A_{w}}}{d t}\right)
\end{gathered}
$$

\section{Turbulence Contribution}

Turbulence action contributes to reduce the variance of the mixture making it more homogeneous. The dissipation of the mixture-fraction variance is representative of the turbulent mixing-process. This contribution is modeled by using an empirical closure term:

$$
\left.\int_{0}^{Z_{s}}\left(Z^{*}-\tilde{Z}\right)^{2} \cdot \frac{d \mathcal{P}\left(Z^{*}\right)}{d t}\right|_{d s} \cdot d Z^{*}=-2 \cdot C_{d i s s} \cdot \frac{\tilde{\epsilon}}{\tilde{\kappa}} \cdot \widetilde{Z " 2}
$$

\section{Global Variance Equation}

Equation (79) because of Equation (80) is reduced to:

$$
\frac{d \widetilde{Z^{\prime 2}}}{d t}=\int_{0}^{Z_{s}}\left(Z^{*}-\tilde{Z}\right)^{2} \cdot \frac{d \mathcal{P}\left(Z^{*}\right)}{d t} \cdot d Z^{*}
$$

Taking advantage of Equations $(84,86,91,95)$ and (96), the right-hand side of Equation (97) can be expressed as:

$$
\begin{gathered}
\frac{d \widetilde{Z^{\prime 2}}}{d t}=\frac{1}{m_{S}} \cdot\left[\tilde{Z}^{2} \cdot\left(\frac{d m_{A}}{d t}+\frac{d m_{A_{w}}}{d t}\right)+\right. \\
\left.+\left(Z_{s}-\tilde{Z}\right)^{2} \cdot \frac{d m_{s}}{d t}-\widetilde{Z^{\prime \prime 2}} \cdot\left(\frac{d m_{A}}{d t}+\frac{d m_{A_{w}}}{d t}+\frac{d m_{s}}{d t}\right)\right]+ \\
-2 \cdot C_{\text {diss }} \cdot \frac{\tilde{\epsilon}}{\tilde{\kappa}} \cdot \widetilde{Z^{\prime \prime 2}}
\end{gathered}
$$

Equation (54) is directly obtained by substituting in Equation (98) the results of Equations $(88,89)$.

Final manuscript received in October 2008 Published online in June 2009 